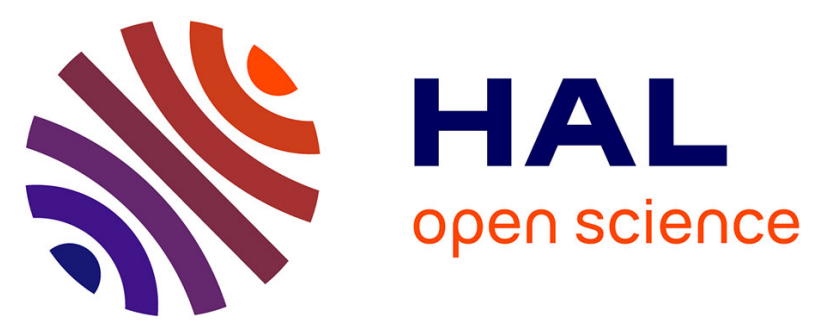

\title{
New insights into the pathogenesis of Beckwith-Wiedemann and Silver-Russell syndromes: contribution of small copy number variations to $11 \mathrm{p} 15$ imprinting defects.
}

Julie Demars, Sylvie Rossignol, Irène Netchine, Kai Syin Lee, Mansur Shmela, Laurence Faivre, Jacques Weill, Sylvie Odent, Salah Azzi, Patrick Callier, et al.

\section{- To cite this version:}

Julie Demars, Sylvie Rossignol, Irène Netchine, Kai Syin Lee, Mansur Shmela, et al.. New insights into the pathogenesis of Beckwith-Wiedemann and Silver-Russell syndromes: contribution of small copy number variations to 11p15 imprinting defects.. Human Mutation, 2011, 32 (10), pp.1171-82. 10.1002/humu.21558 . inserm-00610827

\section{HAL Id: inserm-00610827 https://www.hal.inserm.fr/inserm-00610827}

Submitted on 3 Oct 2014

HAL is a multi-disciplinary open access archive for the deposit and dissemination of scientific research documents, whether they are published or not. The documents may come from teaching and research institutions in France or abroad, or from public or private research centers.
L'archive ouverte pluridisciplinaire HAL, est destinée au dépôt et à la diffusion de documents scientifiques de niveau recherche, publiés ou non, émanant des établissements d'enseignement et de recherche français ou étrangers, des laboratoires publics ou privés. 
Contribution of Small Copy Number Variations to The Pathogenesis of Imprinted 11p15-Related Fetal Growth Disorders

Julie Demars, ${ }^{1}$ Sylvie Rossignol, ${ }^{2}$ Irene Netchine, ${ }^{2}$ Kai Syin Lee, ${ }^{1}$ Mansur Shmela, ${ }^{1}$ Laurence Faivre, ${ }^{3}$ Jacques Weill, ${ }^{4}$ Sylvie Odent, ${ }^{5}$ Salah Azzi, ${ }^{2}$ Patrick Callier, ${ }^{6}$ Josette Lucas, ${ }^{7}$ Christèle Dubourg, ${ }^{8}$ Joris Andrieux, ${ }^{9}$ Yves Le Bouc, ${ }^{2}$ Assam El-Osta, ${ }^{1}$ Christine Gicquel, ${ }^{1 *}$

${ }^{1}$ Epigenetics in Human Health and Disease, Baker IDI Heart and Diabetes Institute, Melbourne, 3004, Victoria, Australia. ${ }^{2}$ APHP, Hôpital Armand Trousseau, Laboratoire d'Explorations Fonctionnelles Endocriniennes, Unité mixte de recherche INSERM UMPC U938, Paris, 75012, France. ${ }^{3}$ Centre de Génétique, CHU Dijon, 21033, France. ${ }^{4}$ Service d'Endocrinologie pédiatrique, Hôpital Jeanne de Flandre, Lille, 59037, France. ${ }^{5}$ Service de Génétique Clinique, CHU Pontchaillou, Rennes, 35203, France. ' Laboratoire de cytogénétique, CHU Dijon, 21033, France. ${ }^{7}$ Laboratoire de cytogénétique, CHU Pontchaillou, Rennes, 35203, France. ¿'Laboratoire de génétique moléculaire, CHU Pontchaillou, Rennes, 35203, France. ${ }^{9}$ Laboratoire de génétique médicale, Hôpital Jeanne de Flandre, Lille, 59037, France.

Key words: genomic imprinting, copy number variation, $11 \mathrm{p} 15$ region, Silver-Russell syndrome, Beckwith-Wiedemann syndrome, fetal growth.

* Correspondence: christine.gicquel@bakeridi.edu.au 


\section{Abstract}

The imprinted $11 \mathrm{p} 15$ region is organized in two domains, each of them under the control of its own imprinting control region (ICR1 for the IGF2/H19 domain and ICR2 for the KCNQ1OT1/CDKN1C domain).

Disruption of $11 \mathrm{p} 15$ imprinting results in two fetal growth disorders with opposite phenotypes: the Beckwith-Wiedemann (BWS) and the SilverRussell (SRS) syndromes. Various 11p15 genetic and epigenetic defects have been demonstrated in BWS and SRS. Among them, isolated DNA methylation defects (ICR1 gain of methylation or ICR2 loss of methylation in BWS and ICR1 loss of methylation in SRS) account for approximately $60 \%$ of patients.

To investigate whether cryptic Copy Number Variations (CNVs) involving only part of one of the two imprinted domains account for $11 \mathrm{p} 15$ isolated DNA methylation defects, we designed a Single Nucleotide Polymorphism array covering the whole $11 \mathrm{p} 15$ imprinted region and genotyped one hundred eighty five SRS or BWS cases with loss or gain of DNA methylation at either ICR1 or ICR2.

We describe herein novel small gain and loss CNVs in six BWS or SRS patients, including maternally-inherited cis-duplications involving only part of one of the domains in SRS and BWS patients. We also show that i) ICR2 deletions do not account for BWS with ICR2 loss of methylation and ii) uniparental isodisomy involving only one of the two imprinted domains is not a mechanism for SRS or BWS.

Those novel defects led new light in the regulation of 11 p15 genomic imprinting. 


\section{Introduction}

Human chromosome 11 p15.5 contains a cluster of imprinted genes that play a crucial role in the control of fetal growth ${ }^{1-4}$. This cluster is organized in two neighboring imprinted domains, the IGF2/H19 and the KCNQ1OT1/CDKN1C domains, each of them under the control of its own imprinting control region, ICR1 and ICR2 respectively. Aberrant genomic imprinting of the $11 \mathrm{p} 15$ region has a pivotal role in both Beckwith-Wiedemann (BWS; MIM 130650) and Silver-Russell (SRS; MIM 180860) syndromes. BWS is characterized by pre-and/or postnatal overgrowth and other features including hemihyperplasia and an increased risk of childhood tumors. SRS is characterized by severe preand postnatal growth retardation, dysmorphic facial features, feeding difficulties and body asymmetry.

Various 11p15 molecular aberrations including genetic and epigenetic abnormalities have been demonstrated in BWS and SRS ${ }^{5-8}$. Among genetic defects, paternal isodisomy of the $11 \mathrm{p} 15$ region involving the two imprinted domains is a classical cause of BWS and accounts for $20-25 \%$ of BWS cases 5, 9, 10, whereas maternal isodisomy has been reported in only one SRS case ${ }^{11}$. Approximately ten unbalanced translocations (gain $\mathrm{CNV}$ ) involving both imprinted domains have also been described. When familial, these translocations result in a fetal growth retardation phenotype when maternally-inherited and an overgrowth phenotype when paternally-inherited, as reviewed in ${ }^{12}$. Nevertheless, epigenetic defects (i.e gain or loss of DNA methylation at either ICR1 or ICR2) are very frequent and account for approximately $60-70 \%$ of BWS and SRS patients. DNA methylation defects involving ICR2 (loss of methylation) result in BWS (60\% of cases) whereas DNA methylation defects involving ICR1 result in both BWS (gain of methylation, $10 \%$ of cases) and SRS (loss of methylation, $50-60 \%$ of cases) ${ }^{5-7,13}$. For a small percentage of those patients, the DNA methylation defect is secondary. Mutations/deletions in ICR1 cis-regulatory elements account for $20 \%$ of BWS patients with ICR1 gain of methylation ${ }^{14-18}$, whereas deletions in ICR2 cis-regulatory elements in BWS patients have been exceptionally reported ${ }^{19,20}$. On the other hand, in a subset of BWS patients $(25 \%)$ with 
ICR2 loss of methylation and SRS patients (10\%) with ICR1 loss of methylation, the loss of methylation involves imprinted loci other than 11 p15 suggesting the dysregulation of an unidentified trans-acting factor controlling the establishment and/or the maintenance of genomic imprinting at several loci ${ }^{21-26}$. Altogether, these secondary DNA methylation defects (deletion of a cis-regulatory element or involvement of a trans-acting regulatory factor) account for a small group of BWS and SRS cases and the mechanism of the DNA methylation defect remains unexplained in most cases.

Conventional diagnostic tools used in $11 \mathrm{p} 15$ fetal growth disorders present either a low resolution level (> $500 \mathrm{~kb}$ ), (i.e caryotype, FISH analysis) or high resolution level $(<5 \mathrm{~kb}$ ), (sequencing, DNA methylation analysis, Multiplex ligation-dependent probe amplification, long-range $\mathrm{PCR}$ ) and they might fail to recognize intermediate CNVs, ranging from 5 to $500 \mathrm{~kb}$. Assessment of small segmental CNVs has not been systematically addressed in SRS and BWS patients with isolated DNA methylation defects. To investigate whether cryptic CNVs account for $11 \mathrm{p} 15$ isolated DNA methylation defects, we designed a customized Single Nucleotide Polymorphism (SNP) array (1536 SNPs) covering the whole 11p15 imprinted region. We genotyped a large series of one hundred eighty five SRS and BWS cases with loss or gain of DNA methylation at either ICR1 or ICR2. We describe herein novel gain and loss CNVs in both BWS and SRS patients. 


\section{Subjects and Methods}

\section{Subjects}

This study was conducted in compliance with institutional guidelines for research studies in human genetics (approval no. 253/07, Alfred Hospital Ethics Committee and agreement numbers 681 and 682, Assistance Publique-Hôpitaux de Paris) and informed consent was obtained from participating individuals and/or their parents. The study population consisted of 50 ethnically matched control subjects and 185 patients with growth disorders caused by a DNA methylation defect of the $11 \mathrm{p} 15$ domain. A subset of BWS and SRS patients with abnormal DNA methylation at ICR1 was analyzed in a previous study ${ }^{18}$. Patients with cytogenetic abnormalities, $11 \mathrm{p} 15$ parental isodisomy or CDKN1C gene mutation and patients with a multilocus imprinting disorder 21; 22 were excluded from the study. Biparental inheritance of the $11 \mathrm{p} 15$ region was shown by Southern-blot and/or microsatellite analysis.

One hundred and thirteen patients were diagnosed with BWS. Seventyeight of them displayed a loss of methylation at ICR2. Thirty-five BWS patients displayed a gain of methylation at ICR1. Nine BWS cases (six with ICR2 loss of methylation and three with ICR1 gain of methylation) were fetal cases (medically terminated pregnancies in $50 \%$ of cases and spontaneous abortion in $50 \%$ of cases). Five BWS cases were familial forms (one with ICR2 loss of methylation and four cases from two families with ICR1 gain of methylation).

Seventy-two patients were SRS patients who displayed loss of methylation at ICR1.

Parental DNA was available for 110 (59\%) BWS or SRS patients. In 93 cases, DNA was available from both parents. Non-paternity was found in three BWS cases with ICR2 loss of DNA methylation and only maternal DNA was considered in those cases.

The clinical and molecular data of BWS and SRS patients are summarized in tables 1 and 2 .

\section{Methods}

\section{Selection of SNP probes and Oligo Pool Assay design}

An Oligo Pool Assay (OPA) of 1536 SNPs covering the whole 11p15 
region (location on chromosome 11: position 1,970,084-2,869,522, NCBI $36 / \mathrm{hg} 18$ assembly) and including the two imprinted domains was designed. To allow a high success rate of genotyping, only SNPs with an Illumina SNP_score $>0.6$ were selected among the 6214 polymorphisms present in dbSNP130 and located in the region of interest. SNPs already genotyped in the HapMap CEU population (our disease panel consists mostly of European individuals) were preferentially chosen. They represent 648 SNPs out of the 1536 final dataset. We selected SNPs dispersed homogenously along the domain with a final density of 1 to 3 probes per kilobase. Moreover, regions corresponding to the two imprinting control regions (ICR1 and ICR2) were enriched with a density of one probe every $300 \mathrm{bp}$. The customized OPA was used to genotype patients, their parents and some of the family members as well as control samples on the iScan System (http://www.illumina.com) according to the manufacturer's protocol.

\section{Preparation of SNP data}

We generated a total of $\sim 735000$ genotypes in 473 samples. Genotypes were analyzed using the Illumina GenomeStudio software (http://www.illumina.com). After reclustering, 8 samples with a call rate $<95 \%$ and 340 probes with excessive noise or aberrant clustering patterns (based on the GenTrain Score and manual inspection) were permanently excluded from further analysis. Following a series of quality control steps, an initial design using 1536 SNPs and 473 individuals was reduced to a final dataset of 1196 SNPs and 465 samples (including the 185 patients and 50 control subjects).

\section{CNVs detection by Illumina and QuantiSNP v2.3 softwares}

Analysis of $C N V$ s was done based on $\log R$ ratio and $B$ allele frequency values issued from the Illumina GenomeStudio and Beadstudio v3.1 softwares. Firstly, we used the cnvPartition v2.4.4 plug-in (http://www.illumina.com) implemented in the Illumina GenomeStudio software to identify CNVs. Given the density of probes in the OPA (one to three per $\mathrm{kb}$ ), CNVs as small as $1 \mathrm{~kb}$ could be potentially detected. We performed a non-stringent analysis considering 3 consecutive probes, a minimum size of $1,000 \mathrm{bp}$ and a threshold of 35 according to the 
program. Because the cnvPartition algorithm uses an undocumented method of CNV detection, we also used the QuantiSNP v2.3 software developed by Colella et al. ${ }^{27}$. QuantiSNP based on Objective Bayes Hidden-Markov Model treats independently $\log R$ ratio and $B$ allele frequency and has been shown to outperform other softwares ${ }^{28}$. The analysis was performed using default parameters ${ }^{27}$ and a score (Log Bayes Factor) was assigned to each identified CNV; only CNVs with a stringent threshold score (Log Bayes Factor $>30$ ) have been considered. Secondly, to identify runs of homozygosity, we used the Homozygosity Detector plug-in (http://www.illumina.com) implemented in the lllumina BeadStudio v3.1 software as well as the QuantiSNP v2.3 software. The analysis was performed using the default parameters of the Homozygosity Detector program. All regions with more than 50 homozygous and a cutoff significance $\chi 2>23.5$ were marked as runs of homozygosity. For the analysis using the QuantiSNP v2.3 software, only runs of homozygosity with a Log Bayes Factor $>30$ were considered.

\section{Validation of identified CNVs by quantitative real-time PCR analysis and CGH array}

Quantitative real-time PCR: Validation of CNVs identified from the SNP array was performed by quantitative real time PCR. We designed at least 5 primer sets located within and outside the region of interest to confirm the CNVs and map their limits. Quantitative real time PCR was carried out by using a 7500 fast real time PCR system (ABI systems) and Fast SYBR green mix (Roche). Data expressed as the relative quantification were normalized to a region located in the neurogenin 1 gene in which no genetic variation has been described. Two normal individuals were included. All primers used in this study are listed in Supplementary table 1.

CGH array: Validation of some CNVs identified from the SNP array was performed using the 244K Agilent - Human CpG Island Microarray Kit (patient S72P) or the $4 \times 180 \mathrm{~K}$ Agilent-Human Genome Microarray Kit (patient H47P) (Agilent Technologies, Santa Clara, CA, USA).

\section{Bisulfite sequencing}


Bisulfite sequencing was performed as previously described ${ }^{18}$. Primers used in this study are listed in Supplementary table 1.

\section{Karyotyping and FISH characterisation}

Chromosomes were prepared from peripheral blood lymphocyte cultures following standard procedures. Fluorescence in situ hybridization (FISH) using chromosome 11 specific subtelomeric probes (patient H47P) was performed according to the manufacturer's specifications (Abbott molecular/Vysis, USA). The BAC probes used in other FISH analyses include RP11-295K3 and RP3-416J11 (patient S72P) and CTD-2242D18 (patient L65P). 


\section{Results}

Several parameters were used to assess the likelihood of pathogenicity of a CNV in this study: $i$ ) the specific localization of a CNV within the $11 \mathrm{p} 15$ region (i.e the $\mathrm{CNV}$ involves key regulatory elements such as ICR2 in BWS patients with loss of methylation involving the centromeric domain or ICR1 in BWS and SRS patients with a DNA methylation defect of the telomeric domain). ii) the parental transmission of the CNV in familial cases: when inherited, a CNV inherited from a healthy parent was considered as potentially pathogenic. iii) copy-neutral CNVs (runs of homozygosity) were considered as potentially pathogenic as losses and gains, as they might reflect segmental uniparental isodisomy. iv) variants that are seen in healthy individuals are less likely to account for a patient's phenotype. To this purpose, the database of genomic variants (http://projects.tcag.ca/variation/) was consulted.

\section{New intermediate CNVs in BWS or SRS patients with DNA methylation defect at ICR1 or ICR2}

Six CNVs (2 deletions and 4 duplications) were identified in six patients, by using the cnvPartition v2.4.4 and/or the QuantiSNP v2.3 softwares (Table 3). Three CNVs (4 to $22 \mathrm{~kb}$ ) were only identified with the cnvPartition software and they were not confirmed by quantitative PCR. Three CNVs, all duplications, were identified with both softwares and were confirmed by quantitative real-time PCR. Those three validated duplications were further characterized.

\section{H47P BWS patient:}

The male patient was a first child, born after 38 weeks of gestation following ovarian stimulation. Prenatal sonography identified cystic hygroma and unilateral pyelectasis. Antenatal karyotype was normal. There was no familial history of BWS. At birth, the patient displayed severe macrosomia (birth length $56 \mathrm{~cm},+3.4$ SD; birth weight $5490 \mathrm{~g},+5.9 \mathrm{SD}$ ), macroglossia, umbilical hernia and facial dysmorphia and the first months of post-natal life were marked by feeding difficulties. In early post-natal life, the patient was diagnosed with developmental delay, expressed primarily in the form of hypotonia and non-specific speech retardation. He walked at the age of 17 months. He underwent pyeloplasty for 
ureteropyelic junction stenosis at the age of 1 year and glossoplasty at the age of 3 years. Physical examination at the age of $5^{1 / 12}$ years showed a slight asymmetry of the face, lower limbs and kidneys and advanced growth (+3.5 SD for height and +4.5 SD for weight).

Analysis of the $11 \mathrm{p} 15$ region showed a partial gain of methylation at ICR1 [methylation index at $72 \%$ (normal: $53.9 \pm 2 \%$ )] with a normal methylation status at ICR2 [methylation index at $45 \%(51.6 \pm 2.5 \%)$ ]. Analysis of SNP array data ( $\log R$ Ratio and $B$ allele frequency) identified a duplication (Figure 1A). The duplication covered the whole IGF2/H19 domain, involving the most telomeric probe (position 1,970,084, NCBI36/hg18 Assembly), with a centromeric breakpoint located within the 3' end of the CD81 gene (between position 2,374,469 and 2,375,108). Quantitative PCR showed that the duplication extends to the telomeric end of the short arm (Figure 1B) refining the size of the duplication to approximately 2.4 $\mathrm{Mb}$. SNP analysis showed that the duplication involved the paternal allele (Figure 1C). CGH array confirmed the telomeric duplication at 11p15.5 and also identified a $2 \mathrm{Mb}$ telomeric deletion at 11q25 (breakpoint between position 132,431,292 and 134,432,465) (Figure 1D). Metaphase FISH analysis of H47P with a $11 \mathrm{p}$ subtelomeric probe showed signals at both telomeres of a derivative chromosome 11, whereas FISH analysis using a 11q subtelomeric probe confirmed a deletion of 11qter by showing a fluorescent signal on the normal chromosome 11 only (Figure 1E). FISH analysis in parents identified a pericentric inversion in the father, with the $11 p$ subtelomeric probe hybridizing the end of $11 q$ and the $11 q$ subtelomeric probe hybridizing the end of $11 \mathrm{p}$ on the inverted chromosome (Figure 1E). As the size of the inverted segment is in the range of $130 \mathrm{Mb}$, the karyotypes were considered as normal in both H47P and his father (data not shown). This observation shows that partial trisomy $11 \mathrm{p} 15$ and partial monosomy 11q25 in H47P resulted from unequal crossing over during paternal meiosis.

\section{S72P SRS patient:}

The female patient was the second child, conceived naturally from non consanguineous parents (Figure 2A). At birth (term of 36 weeks), she displayed intrauterine growth retardation [birth weight of $1690 \mathrm{~g}$ (-2.6 SD), 
birth length of $39.5 \mathrm{~cm}(-4.4 \mathrm{SD})]$ with relative macrocephaly (-0.4 SD). Early postnatal life was marked by severe feeding difficulties and growth deceleration ( -3 SD at the age by 7 months and -3.7 SD by the age of 15 months) with a BMI of $-2 \mathrm{SD}$. SRS was diagnosed during the second year of life on the basis of postnatal growth retardation with conserved head circumference, bossed forehead, clinodactyly of the fifth digits, body asymmetry and feeding difficulties. The parents and the older brother were clinically normal and there was no familial history of SRS on the maternal side.

Analysis of the $11 \mathrm{p} 15$ region showed a partial loss of methylation at ICR1 (methylation index at 25\%) with a normal methylation status at ICR2 (methylation index at $47 \%$ ). Analysis of SNP array data identified a maternally-inherited duplication covering part of the IGF2/H19 domain, including the $\mathrm{H} 19$ gene and ICR1 but not the IGF2 gene (Figure 2B). Characterization of the duplication by quantitative PCR and CGH array estimated its size between 562 and $575 \mathrm{~kb}$ with the telomeric breakpoint located between 1,522,259 and 1,530,602 bp (within the HCCA2 gene) and the centromeric breakpoint located between 2,092,578 and 2,097,357 bp (Figures 2C and 2D). Two color FISH analysis of S72P and her mother with two BAC probes (RP11-295K3 within the duplication and RP3-416J11 outside the duplication) excluded an unbalanced translocation and showed an increased signal at $11 p$ with RP11-295K3, providing indirect evidence for cis-duplication of the affected region (Figure 2E). FISH on S72P's interphased nuclei clearly showed three hybridization signals confirming the cis-duplication (Figure 2F). Methylation analysis in the mother showed a gain of methylation at ICR1 (methylation index at 68\%). The mother's phenotype was normal and no clinical history in early childhood was indicative of BWS. Both maternal grandparents had normal phenotypes and there was no familial history suggesting SRS or BWS cases. Assuming that the grand paternal allele was methylated in the mother, we performed genomic and bisulfite sequencing of the ICR1 B6 repeat $(1,980,297-1,980,616$ bp) in S72P and her mother. An allelic imbalance was observed for the informative rs61383602 SNP in the mother, suggesting that the $C$ allele was the duplicated allele (Figure $2 \mathrm{G}$ ). Bisulfite 
sequencing showed that in the mother, the duplicated $C$ allele peak was methylated confirming that the duplication originated from the maternal grandfather (Figure 2G).

Familial L65P BWS case: The family was previously reported as a clinical description in $1983^{29}$. All the affected subjects were conceived from normal sisters (Figure 3A). Patient L65P (III.7, Figure 3A) was born after 40 weeks of a normal gestation from non consanguineous parents. The clinical presentation at birth included macroglossia, exomphalos, hypospadias, bilateral cryptorchidism, bilateral inguinal hernias, posterior helical pits and severe neonatal hypoglycemia. Patient L65P had no macrosomia at birth (birth weight $3200 \mathrm{gr},-0.6 \mathrm{SD}$ ) but then displayed advanced growth (+2.5 SD at the age of 5 years) with a final height at 196 $\mathrm{cms}(+2.8 \mathrm{SD})$. The familial history includes three other cases. The first pregnancy of individual II.1 was complicated at five months of gestation by acute hydramnios resulting in fetal death. Pathologic findings of the male fetus (III.1) included exomphalos, adrenal cytomegaly and leydigian hyperplasia. A second pregnancy was terminated after 25 weeks of gestation after ultrasound examination showed an exomphalos. The first pregnancy of individual II.4 was also terminated after 18 weeks of gestation after ultrasound diagnosis of exomphalos. Pathologic findings of the female fetus (III.8) included exomphalos, adrenal cytomegaly and ovarian hyperplasia. A second pregnancy resulted in spontaneous abortion at 9 weeks. Analysis of the 11p15 region showed a complete loss of methylation at ICR2 in patient III.7 whereas the ICR2 methylation status in the mother (II.3) and her two sisters (II.1 and II.4), obligate carriers, was normal (Figure 3B). The ICR2 methylation pattern was also normal in the individuals whom DNA was available, including the maternal grandmother (Figure 3B). Search for a deletion involving ICR2 was negative (PCR and quantitative PCR) and this hypothesis was unlikely as the ICR2 DNA methylation profile was normal in L65P's mother and her sisters. ICR2 was also sequenced (position 2,677,063 to 2,679,536 bp) and no small deletions or mutations were identified.

Analysis of SNP array and Log R Ratio data identified an approximately 50 $\mathrm{kb}$ duplication ranging from approximately $2,485,000$ to $2,533,000 \mathrm{bp}$ 
(Figure $3 C$ ), involving the $3^{\prime}$ part of intron 1 , exon 2 and 5 ' part of intron 2 of the KCNQ1 gene (isoform NM000218.2). The duplication was confirmed by quantitative PCR with the telomeric breakpoint located between $2,472,581$ and 2,486,398 bp and the centromeric breakpoint located between 2,526,347 and 2,540,424 bp (Figure 3D). The duplication was also found in the three sisters (obligate carriers) and also in unaffected individuals II.5 and III.5. Subject I.1 did not display the duplication (Figures $3 C$ and $3 D$ ), suggesting that the duplication was transmitted from L65P's maternal grandfather (DNA not available) to the five siblings (II.1 to II.5). The duplication was also absent in the only unaffected child (III.3) born from one (II.1) of the three sisters (Figures $3 \mathrm{~A}$ and $3 \mathrm{D}$ ). FISH analysis with the CTD-2242D18 probe (position: 2,469,461-2,575,865) did not detect an increased hybridization signal on chromosome 11 . It is likely that the small size of the duplication prevented its identification by FISH. The absence of an extra signal on another chromosome is in favor of a $11 \mathrm{p} 15$ cisduplication.

As the duplication encompasses two CpG islands, we investigated the methylation status of those CpG islands in three control subjects, L65P, his mother (II.3) and his maternal grandmother (I.1). Bisulfite sequencing analysis of the CpG island in position 2,510,680-2,510,907 showed that both parental alleles were unmethylated (Figure $3 \mathrm{~F}$ ) in control subjects, patient L65P and subjects II.3 and I.1. Analysis of the CpG island in position 2,511,982-2,512,194 showed that the CpG island was predominantly methylated with no allele-specific DNA methylation in controls (Figure 3F). In patient L65P, subjects II.3 and I.1, the DNA methylation pattern was the same as in control subjects.

\section{Small CNVs in BWS patients with gain of DNA methylation at ICR1}

A few ICR1 deletions have been previously reported, essentially in BWS patients. They are small in the range of $1-2 \mathrm{~kb}$ and as they involve very few markers, they might be missed by the CNV detection methods. We therefore performed an accurate analysis of respective imprinting control regions in patients with abnormal DNA methylation at ICR1 or ICR2, assuming that homozygous calls (B allele frequency) with a reduced copy 
number (log R ratio) for SNPs mapping to ICR1 (1,976,000-1,981,000 bp) or ICR2 $(2,676,000-2,679,000 \mathrm{bp})$ will reflect the occurence of a hemizygous deletion.

Three BWS patients with ICR1 gain of methylation displayed a low log $R$ ratio for two or three SNPs located within ICR1 (Figure 4A). Two of them, $\mathrm{H} 32 \mathrm{P}$ (previously reported, ${ }^{18}$ ) and H5OP presented as apparently sporadic BWS cases. H63P had a familial history of Wilms tumors on the maternal side (Figure 4B). H63P's mother herself displayed a phenotype indicative of BWS, including macrosomia at birth, organomegaly and body asymmetry. She also developed a Wilms tumor when she was 5 years old. Deletions were characterized by long range PCR, quantitative PCR and sequencing (Figures 4C, 4D and 4E). All deletions were maternallyinherited (Figure 4C). The two 1834 bp deletions (H32P and H50P) fusion blocks $\mathrm{B} 6$ with $\mathrm{B} 3$, removing two CTCF binding sites but involve different breakpoints (Figure 4F and Table 4). The 2240 bp H63P deletion fusions blocks B6 with B2 and removes CTCF binding sites 2, 3 and 4 (Figures 4E, 4F and Table 4).

No ICR1 deletion was detected in a series of 72 SRS patients displaying ICR1 loss of methylation. Similarly, investigation of a large series of 78 BWS with ICR2 loss of methylation did not identify any deletion.

\section{Copy neutral CNVs}

Copy neutral CNVs correspond to runs of homozygosity without any change in copy number. They might reflect uniparental isodisomy (UPiD) or autozygosity. UPiDs previously identified in BWS and SRS patients involve both ICR1 and ICR2 and display a mosaic pattern. The density of the SNP array and the availability of parental DNA for $60 \%$ of patients made possible the identification of segmental UPiDs. Analysis of the data for shift in B allele frequency for heterozygous SNPs (not centered at 0.5), associated with a normal $\log \mathrm{R}$ ratio and mendelian inconsistency (when parental DNA was available) did not identify mosaic segmental UPiD in SRS or BWS patients with loss or gain of DNA methylation at either ICR1 or ICR2.

However, runs of homozygosity, ranging from 86 to $335 \mathrm{~kb}$ (156 to 592 
probes) were identified in the various groups of patients and controls (Figure 5). Although runs of homozygosity were identified within the whole 11 p15 region, two locations were overrepresented after analysis with the two softwares. The first region (position 2,170,000 to 2,270,000 bp), encompassing the paternally-imprinted ASCL2 gene, was homozygous in $17 \%$ of both patients and controls (Box A in Figure 5 and supplementary Table 2). The second region (position 2,270,000 to 2,370,000 bp), encompassing the C11ORF21 and TSPAN32 genes, was homozygous in $23 \%$ and $15 \%$ of patients and controls respectively (Box B in Figure 5 and supplementary Table 2). 


\section{Discussion}

Recent modifications to SNP arrays enhance the opportunity to discover CNVs along with concomitant SNP genotypes. We designed a custom SNP array to target the analysis to the $11 \mathrm{p} 15$ region including the two imprinting control regions and investigate whether intermediate lesions (which cannot be recognized by routine diagnostic tools) account for a subset of 11p15 growth disorders with abnormal DNA methylation at either ICR1 or ICR2. A SNP array was favored to CGH array as it has the ability to (i) simultaneously measure both intensity differences and allelic ratios and therefore to investigate both DNA copy-number and copy-neutral variation and (ii) identify the parental origin of CNVs.

- We identified three novel duplications which have not been previously described.

Two duplications involved the IGF2/H19 domain. In the H47P BWS case, $\mathrm{CGH}$ showed that a $2 \mathrm{Mb}$ deletion of the distal part of $11 \mathrm{q}$ was associated with an apparently de novo $2.4 \mathrm{Mb}$ duplication of the whole IGF2/H19 domain on the paternal chromosome. FISH analysis of H47P and his parents demonstrated that H47P displayed recombination of a paternallyinherited pericentric inversion of chromosome 11, with a large inverted segment of approximately $130 \mathrm{Mb}$ (i.e more than $95 \%$ of the chromosome). A few $11 \mathrm{p}$ pericentric inversions have been previously described ${ }^{30-32}$, some of them with a predominant BWS phenotype ${ }^{30}$. Those previously described pericentric inversions led to the duplication of the whole $11 \mathrm{p} 15$ imprinted domain with breakpoints between 11p13 and 11p15.1. The H47P case is unique as the duplication of the short arm involves only part of the $11 \mathrm{p} 15$ imprinted region (i.e the IGF2/H19 domain). The deletion of 11q25 involves 10 genes and might account for the developmental delay.

The second duplication of the IGF2/H19 domain represents the first observation of a genetic abnormality within the IGF2/H19 domain in SRS. The S72P cis-duplication involves only part of the IGF2/H19 domain (the imprinting control region and the $H 19$ gene) and results in a SRS phenotype only if maternally-inherited when there is no phenotype upon paternal transmission. Both the parental transmission pattern and the 
phenotype are different from previously reported ICR1 duplications ${ }^{12,33,34}$. Cis-duplications ( 0.3 to $1.8 \mathrm{Mb}$ in size) involving the whole IGF2/H19 domain have been previously reported in two familial ${ }^{12,34}$ and one sporadic ${ }^{33}$ BWS cases. They resulted in a BWS only if the paternal chromosome was involved. The main difference between the S72P duplication and other duplications of the IGF2/H19 domain $\left({ }^{12,33,34}\right.$ and the $\mathrm{H} 47 \mathrm{P}$ case) is that the S72P duplication involves ICR1 and the H19 gene but does not involve the IGF2 gene. Hence, a partial maternal cisduplication of the IGF2/H19 domain results in a SRS phenotype (S72P case) whereas a maternal cis-duplication involving the whole IGF2/H19 domain does not result in any phenotype ${ }^{12}$ (Supplementary figure 1). Although two copies of the active maternal $\mathrm{H} 19$ gene are expressed in both cases, the chromatin organization is likely to be different. In the partial cis-duplication, one maternal $\mathrm{H} 19$ gene is not engaged in a ciseffect. It was recently shown that, apart from a cis-effect, the H19 noncoding RNA also regulates the expression of lgf2 by a transacting mechanism ${ }^{35}$. Indeed, $\mathrm{H} 19$ transgenic expression is able to rescue the overgrowth phenotype of mice with targeted deletions of the $\mathrm{H} 19$ gene and also to reduce Igf2 expression ${ }^{35}$. We hypothesize that an extra copy of a functional maternal $\mathrm{H} 19$ gene (not engaged in a cis-effect) can affect the expression of IGF2 by a transacting mechanism and result in growth retardation. Two deletions within or overlapping the S72P duplicated region have been registered as rare variations, in apparently normal subjects (http://projects.tcag.ca/variation/; variations 29891, 29893), but the parental origin of these deletions are not known.

The third duplication case is a familial BWS case with ICR2 loss of methylation, involving four affected subjects conceived from three phenotypically normal sisters. The pattern of transmission of this cisduplication supports its pathogenicity with no phenotype when the duplication is transmitted through the male germline and a BWS phenotype when the duplication is transmitted through the female germline. Moreover, the absence of the duplication in an unaffected subject born from a female carrier strengthens the significance of the duplication. Little is known on the centromeric 11 p15 imprinting region 
apart from the ICR2 imprinting control region. One deletion within the L65P duplicated region has been registered as a rare variation (http://projects.tcag.ca/variation/; variation 29897) but the parental origin of this deletion is not known. Nevertheless, the $50 \mathrm{~kb}$ cis-duplication region displays evidence of open chromatin and encompasses two $\mathrm{CpG}$ islands and three CTCF binding sites. Analysis of the DNA methylation status of the two CpG islands had not been previously documented. Those two $\mathrm{CpG}$ islands are not allele-specific differentially methylated in control subjects, with one being predominantly methylated and the other one unmethylated. In the patient displaying the cis-duplication, we showed that the pattern of DNA methylation was similar to the pattern of control subjects. The location of the duplication also corresponds to the centromeric breakpoint of a $1.8 \mathrm{Mb}$ cis-duplication responsible for a BWS 33 and the Tm87-16 rhabdoid tumor translocation breakpoint within BWSCR $1{ }^{36,37}$. All together, this data strongly supports the relevance of the cis-duplication in the BWS phenotype and suggests that the cis-duplication affects the chromatin conformation and impairs the apposition and/or maintenance of DNA methylation at ICR2.

- Precise analysis of the two imprinting control regions (ICR1 and ICR2) led to the identification of new small deletions. Those deletions were only identified in BWS patients with ICR1 gain of methylation. As for previous identified deletions ${ }^{18}$, the deletion breakpoints in those new cases map repetitive sequences within the $B$ repeats of ICR1, suggesting that these repetitive sequences within ICR 1 promote the risk of deletion. No ICR1 deletions were identified in SRS patients with ICR1 loss of methylation and this agrees with previous publications which show the absence of phenotype upon paternal transmission of ICR1 deletions ${ }^{14,16}$. Moreover, we did not identify ICR2 deletions in this large series of BWS patients with ICR2 loss of methylation. Although ICR2 deletions ( 0.25 and $0.9 \mathrm{Mb}$ ) have been occasionally reported in BWS with loss of methylation at ICR2 ${ }^{19,20}$, the data presented here establishes that they are extremely rare.

- A major advantage of the SNP array is the possibility to combine detection of gain/loss CNVs with copy-neutral CNVs (runs of homozygosity). Such segments of homozygosity could represent 
uniparental isodisomy or autozygosity. Uniparental isodisomy is a classical cause of BWS and accounts for 20 to $25 \%$ of BWS cases ${ }^{59}$, 10 , whereas maternal isodisomy has been reported in only one SRS case ${ }^{11}$. When the frequency of uniparental isodisomy is well established in BWS, its extent on chromosome 11 has not been extensively analyzed. In a recent study, Cooper et al. showed that the extent of isodisomy along chromosome 11 is variable but always involves the two $11 \mathrm{p} 15.5$ imprinted domains ${ }^{10}$. In this study, we investigated for the first time whether smaller uniparental isodisomies, confined to one of the two $11 \mathrm{p} 15$ imprinted domains, might account for DNA methylation defects restricted to ICR1 or ICR2. Although we identified runs of homozygosity in BWS and SRS patients, the B allele frequency was not indicative of mosaicism and there was no mendelian inconsistency when parental DNA was available. This data shows that segmental uniparental isodisomies confined to the IGF2/H19 or the KCNQ1OT1/CDKN1C domains do not account for DNA methylation defects restricted to one of the two 11p15 imprinted domains.

In summary, investigation by SNP array of a large series of BWS and SRS patients with isolated ICR1 or ICR2 DNA methylation defects led to the identification of new molecular defects including novel segmental cisduplications in both SRS and BWS patients and new ICR1 deletions in BWS patients. This study also establishes, for the first time, that segmental uniparental isodisomies do not account for isolated ICR1 or ICR2 DNA methylation defects. We also demonstrate in a large series of BWS patients that ICR2 deletions are not a common mechanism for loss of methylation at ICR2.

Our data also illustrates the difficulty of genetic counseling in patients with 11 p15 related growth disorders. Indeed, in more than $50 \%$ of cases, the clinical presentation was sporadic rather than familial despite a maternallyinherited genetic defects. This study and a previous one ${ }^{18}$ also emphasize that molecular defects in cis are more common than initially thought in BWS patients with ICR1 gain of methylation and affect at least $20 \%$ of cases.

\section{Supplemental Data:}

Supplemental Data include one figure and two tables and can be found 
online at http://www.

\section{Acknowledgments:}

We thank Annick Blaise for her technical assistance and the physicians for patients' referrals and collection of clinical data. We are grateful to the willingness of the patients and their families to contribute to this study.

\section{Funding:}

This work was supported by the National Health and Medical Research Council of Australia (Project grant 472637), the Baker IDI Heart and Diabetes Institute, the Institut National de la Santé et de la Recherche Médicale UMPC U938, Université Pierre et Marie Curie Paris 6 and Assistance Publique Hopitaux de Paris.

Conflict of interest statement. None declared.

\section{Web Resources:}

The URLs for data presented herein are as follows:

Online Mendelian Inheritance in Man (OMIM), http://www.ncbi.nlm.nih.gov/Omim/; International HapMap Project: http://www.hapmap.org/; Database of genomic variants: http://projects.tcag. ca/variation; UCSC Genome Browser, March 2006 build, http://genome. cse.ucsc.edu/ 


\section{References:}

1. Reik, W., and Walter, J. (2001). Genomic imprinting: parental influence on the genome. Nat Rev Genet 2, 21-32.

2. Delaval, K., and Feil, R. (2004). Epigenetic regulation of mammalian genomic imprinting. Curr Opin Genet Dev 14, 188-195.

3. Gicquel, C., and Le Bouc, Y. (2006). Hormonal regulation of fetal growth. Horm Res 65 Suppl 3, 28-33.

4. Hudson, Q.J., Kulinski, T.M., Huetter, S.P., and Barlow, D.P. (2010). Genomic imprinting mechanisms in embryonic and extraembryonic mouse tissues. Heredity. 105, 45-56.

5. Gaston, V., Le Bouc, Y., Soupre, V., Burglen, L., Donadieu, J., Oro, H., Audry, G., Vazquez, M.P., and Gicquel, C. (2001). Analysis of the methylation status of the KCNQ1OT and $\mathrm{H} 19$ genes in leukocyte DNA for the diagnosis and prognosis of Beckwith-Wiedemann syndrome. Eur J Hum Genet 9, 409418.

6. Cooper, W.N., Luharia, A., Evans, G.A., Raza, H., Haire, A.C., Grundy, R., Bowdin, S.C., Riccio, A., Sebastio, G., Bliek, J., et al. (2005). Molecular subtypes and phenotypic expression of Beckwith-Wiedemann syndrome. Eur J Hum Genet 13, 1025-1032.

7. Gicquel, C., Rossignol, S., Cabrol, S., Houang, M., Steunou, V., Barbu, V., Danton, F., Thibaud, N., Le Merrer, M., Burglen, L., et al. (2005). Epimutation of the telomeric imprinting center region on chromosome 11p15 in SilverRussell syndrome. Nat Genet 37, 1003-1007.

8. Weksberg, R., Shuman, C., and Beckwith, J.B. (2010). BeckwithWiedemann syndrome. Eur J Hum Genet 18, 8-14.

9. Henry, I., Bonaiti-Pellie, C., Chehensse, V., Beldjord, C., Schwartz, C., Utermann, G., and Junien, C. (1991). Uniparental paternal disomy in a genetic cancer-predisposing syndrome. Nature 351, 665-667.

10. Cooper, W.N., Curley, R., Macdonald, F., and Maher, E.R. (2007). Mitotic recombination and uniparental disomy in Beckwith-Wiedemann syndrome. Genomics 89, 613-617.

11. Bullman, H., Lever, M., Robinson, D.O., Mackay, D.J., Holder, S.E., and Wakeling, E.L. (2008). Mosaic maternal uniparental disomy of chromosome 11 in a patient with Silver-Russell syndrome. J Med Genet 45, 396-399. 
12. Bliek, J., Snijder, S., Maas, S.M., Polstra, A., van der Lip, K., Alders, M., Knegt, A.C., and Mannens, M.M. (2009). Phenotypic discordance upon paternal or maternal transmission of duplications of the $11 \mathrm{p} 15$ imprinted regions. Eur J Med Genet 52, 404-408.

13. Netchine, I., Rossignol, S., Dufourg, M.N., Azzi, S., Rousseau, A., Perin, L., Houang, M., Steunou, V., Esteva, B., Thibaud, N., et al. (2007). 11p15 imprinting center region 1 loss of methylation is a common and specific cause of typical Russell-Silver syndrome: clinical scoring system and epigeneticphenotypic correlations. J Clin Endocrinol Metab 92, 3148-3154.

14. Sparago, A., Cerrato, F., Vernucci, M., Ferrero, G.B., Silengo, M.C., and Riccio, A. (2004). Microdeletions in the human H19 DMR result in loss of IGF2 imprinting and Beckwith-Wiedemann syndrome. Nat Genet 36, 958-960.

15. Prawitt, D., Enklaar, T., Gartner-Rupprecht, B., Spangenberg, C., Oswald, M., Lausch, E., Schmidtke, P., Reutzel, D., Fees, S., Lucito, R., et al. (2005). Microdeletion of target sites for insulator protein CTCF in a chromosome 11 p15 imprinting center in Beckwith-Wiedemann syndrome and Wilms' tumor. Proc Natl Acad Sci U S A 102, 4085-4090.

16. Sparago, A., Russo, S., Cerrato, F., Ferraiuolo, S., Castorina, P., Selicorni, A., Schwienbacher, C., Negrini, M., Ferrero, G.B., Silengo, M.C., et al. (2007). Mechanisms causing imprinting defects in familial BeckwithWiedemann syndrome with Wilms' tumour. Hum Mol Genet 16, 254-264.

17. Scott, R.H., Douglas, J., Baskcomb, L., Huxter, N., Barker, K., Hanks, S., Craft, A., Gerrard, M., Kohler, J.A., Levitt, G.A., et al. (2008). Constitutional 11 p15 abnormalities, including heritable imprinting center mutations, cause nonsyndromic Wilms tumor. Nat Genet 40, 1329-1334.

18. Demars, J., Shmela, M.E., Rossignol, S., Okabe, J., Netchine, I., Azzi, S., Cabrol, S., Le Caignec, C., David, A., Le Bouc, Y., et al. (2010). Analysis of the IGF2/H19 imprinting control region uncovers new genetic defects, including mutations of OCT-binding sequences, in patients with $11 \mathrm{p} 15$ fetal growth disorders. Hum Mol Genet 19, 803-814.

19. Niemitz, E.L., DeBaun, M.R., Fallon, J., Murakami, K., Kugoh, H., Oshimura, M., and Feinberg, A.P. (2004). Microdeletion of LIT1 in familial Beckwith-Wiedemann syndrome. Am J Hum Genet 75, 844-849.

20. Zollino, M., Orteschi, D., Marangi, G., De Crescenzo, A., Pecile, V., Riccio, 
A., and Neri, G. (2010). A case of Beckwith-Wiedemann syndrome caused by a cryptic $11 \mathrm{p} 15$ deletion encompassing the centromeric imprinted domain of the BWS locus. J Med Genet 47, 429-432.

21. Rossignol, S., Steunou, V., Chalas, C., Kerjean, A., Rigolet, M., ViegasPequignot, E., Jouannet, P., Le Bouc, Y., and Gicquel, C. (2006). The epigenetic imprinting defect of patients with Beckwith-Wiedemann syndrome born after assisted reproductive technology is not restricted to the $11 \mathrm{p} 15$ region. J Med Genet 43, 902-907.

22. Azzi, S., Rossignol, S., Steunou, V., Sas, T., Thibaud, N., Danton, F., Le Jule, M., Heinrichs, C., Cabrol, S., Gicquel, C., et al. (2009). Multilocus methylation analysis in a large cohort of 11p15-related foetal growth disorders (Russell Silver and Beckwith Wiedemann syndromes) reveals simultaneous loss of methylation at paternal and maternal imprinted loci. Hum Mol Genet 18, 4724-4733.

23. Bliek, J., Alders, M., Maas, S.M., Oostra, R.J., Mackay, D.M., van der Lip, K., Callaway, J.L., Brooks, A., van 't Padje, S., Westerveld, A., et al. (2009). Lessons from BWS twins: complex maternal and paternal hypomethylation and a common source of haematopoietic stem cells. Eur J Hum Genet 17, 1625-1634.

24. Bliek, J., Verde, G., Callaway, J., Maas, S.M., De Crescenzo, A., Sparago, A., Cerrato, F., Russo, S., Ferraiuolo, S., Rinaldi, M.M., et al. (2009). Hypomethylation at multiple maternally methylated imprinted regions including PLAGL1 and GNAS loci in Beckwith-Wiedemann syndrome. Eur J Hum Genet 17, 611-619.

25. Lim, D., Bowdin, S.C., Tee, L., Kirby, G.A., Blair, E., Fryer, A., Lam, W., Oley, C., Cole, T., Brueton, L.A., et al. (2009). Clinical and molecular genetic features of Beckwith-Wiedemann syndrome associated with assisted reproductive technologies. Hum Reprod 24, 741-747.

26. Meyer, E., Lim, D., Pasha, S., Tee, L.J., Rahman, F., Yates, J.R., Woods, C.G., Reik, W., and Maher, E.R. (2009). Germline mutation in NLRP2 (NALP2) in a familial imprinting disorder (Beckwith-Wiedemann Syndrome). PLoS Genet 5, e1000423.

27. Colella, S., Yau, C., Taylor, J.M., Mirza, G., Butler, H., Clouston, P., Bassett, A.S., Seller, A., Holmes, C.C., and Ragoussis, J. (2007). QuantiSNP: 
an Objective Bayes Hidden-Markov Model to detect and accurately map copy number variation using SNP genotyping data. Nucleic Acids Res 35, 20132025.

28. Dellinger, A.E., Saw, S.M., Goh, L.K., Seielstad, M., Young, T.L., and Li, Y.J. (2010). Comparative analyses of seven algorithms for copy number variant identification from single nucleotide polymorphism arrays. Nucleic Acids Res 38, e105.

29. Nivelon-Chevallier, A., Mavel, A., Michiels, R., and Bethenod, M. (1983). [Familial Wiedeman-Beckwith syndrome: prenatal echography diagnosis and histologic confirmation]. J Genet Hum 31 Suppl 5, 397-402.

30. Waziri, M., Patil, S.R., Hanson, J.W., and Bartley, J.A. (1983). Abnormality of chromosome 11 in patients with features of Beckwith-Wiedemann syndrome. J Pediatr 102, 873-876.

31. Stratakis, C.A., Turner, M.L., Lafferty, A., Toro, J.R., Hill, S., Meck, J.M., and Blancato, J. (2001). A syndrome of overgrowth and acromegaloidism with normal growth hormone secretion is associated with chromosome 11 pericentric inversion. J Med Genet 38, 338-343.

32. Gadzicki, D., Baumer, A., Wey, E., Happel, C.M., Rudolph, C., Tonnies, H., Neitzel, H., Steinemann, D., Welte, K., Klein, C., et al. (2006). Jacobsen syndrome and Beckwith-Wiedemann syndrome caused by a parental pericentric inversion inv(11)(p15q24). Ann Hum Genet 70, 958-964.

33. Russo, S., Finelli, P., Recalcati, M.P., Ferraiuolo, S., Cogliati, F., Dalla Bernardina, B., Tibiletti, M.G., Agosti, M., Sala, M., Bonati, M.T., et al. (2006). Molecular and genomic characterisation of cryptic chromosomal alterations leading to paternal duplication of the 11p15.5 Beckwith-Wiedemann region. J Med Genet 43, e39.

34. Algar, E.M., St Heaps, L., Darmanian, A., Dagar, V., Prawitt, D., Peters, G.B., and Collins, F. (2007). Paternally inherited submicroscopic duplication at 11p15.5 implicates insulin-like growth factor II in overgrowth and Wilms' tumorigenesis. Cancer Res 67, 2360-2365.

35. Gabory, A., Ripoche, M.A., Le Digarcher, A., Watrin, F., Ziyyat, A., Forne, T., Jammes, H., Ainscough, J.F., Surani, M.A., Journot, L., et al. (2009). H19 acts as a trans regulator of the imprinted gene network controlling growth in mice. Development 136, 3413-3421. 
36. Lee, M.P., Hu, R.J., Johnson, L.A., and Feinberg, A.P. (1997). Human KVLQT1 gene shows tissue-specific imprinting and encompasses BeckwithWiedemann syndrome chromosomal rearrangements. Nat Genet 15, 181-185. 37. Prawitt, D., Enklaar, T., Klemm, G., Gartner, B., Spangenberg, C., Winterpacht, A., Higgins, M., Pelletier, J., and Zabel, B. (2000). Identification and characterization of MTR1, a novel gene with homology to melastatin (MLSN1) and the trp gene family located in the BWS-WT2 critical region on chromosome 11p15.5 and showing allele-specific expression. Hum Mol Genet 9, 203-216.

38. Schonherr, N., Meyer, E., Roos, A., Schmidt, A., Wollmann, H.A., and Eggermann, T. (2007). The centromeric $11 \mathrm{p} 15$ imprinting centre is also involved in Silver-Russell syndrome. J Med Genet 44, 59-63. 
Figures titles and legends:

Figure 1: ICR1 duplication resulting from recombination of a paternal pericentric inversion in a BWS patient with ICR1 gain of methylation

(A) Graphical overview of B allele frequency and log R Ratio obtained from the SNP array in H47P and his parents, showing a duplication of the IGF2/H19 domain in H47P. The location of the duplication is highlighted by the grey box. (B) Genomic real-time PCR quantification assay at various loci along the IGF2/H19 domain validating the duplication. (C) Sequencing at various informative SNPs within the duplication showing that the duplication involves the paternally-inherited allele. (D) Graphical overview of the results obtained from the array-CGH analysis of H47P, showing a distal $11 p$ duplication and a distal 11q deletion. (E) FISH analysis with subtelomeric probes for $11 p$ (green) and 11q (red). The normal chromosome 11 has one green and one red signal for $11 p$ and $11 q$, respectively. In H47P, the recombinant chromosome 11 [rec(11) dup $p$ inv(11)] has green signals for $11 p$ on both ends and no red signal. In H47P's father, the inverted chromosome 11 [inv(11) p15.5q25] has a red signal on $11 p$ and a green signal on 11q. Small white arrows indicate the centromeres.

Figure 2: Familial ICR1 duplication in a SRS patient with ICR1 loss of methylation

(A) Pedigree of the S72P SRS case. (B) Graphical overview of B allele frequency and $\log R$ Ratio obtained from the SNP array in S72P and her parents, showing a maternally-inherited segmental duplication of part of the IGF2/H19 domain in S72P. The location of the duplication is highlighted by the grey box. (C) Genomic real-time PCR quantification assay at various loci along the IGF2/H19 domain validating the duplication in S72P and her mother. (D) Graphical overview of the results obtained from the array-CGH analysis of S72P. The duplication interval (from $1,530,602$ to $2,092,578 \mathrm{bp}$ ) is underlined with the pink rectangle. (E) Partial metaphases of patient S72P. FISH with the BAC probe RP11$295 \mathrm{~K} 3$ within the duplication shows an increased hybridization signal (green signal) on one of the chromosomes 11 (arrow) when the signal with the BAC probe RP3-416J11 outside the duplication (red signal) is similar 
on both chromosomes. (F) FISH on S72P's interphased nuclei with the BAC probe RP11-295K3 shows three hybridization signals confirming the duplication. (G) Chromatograms of the ICR1 B6 repeat including SNP rs61383602 (framed in red) before and after bisulfite treatment for patient S72P and her mother. After bisulfite treatment, patient S72P (non informative for the polymorphism) displays a $T$ allele peak (unmethylated duplicated maternal allele) higher than the $C$ allele peak (methylated paternal allele). In the mother, informative for the polymorphism, before treatment by bisulfite, the $C$ allele peak is higher than the $T$ allele confirming the duplication. The profile is the same after bisulfite treatment showing that the $\mathrm{C}$ methylated allele was inherited from the maternal grandfather.

\section{Figure 3: Familial ICR2 BWS case}

(A) Pedigree of the familial BWS case and segregation. Subjects identified with the duplication are indicated with a star. SB: stillbirth. (B) DNA methylation at ICR2, assayed by methyl-sensitive Southern blotting using genomic DNA from the indicated individuals. The upper band $(6 \mathrm{~kb})$ is methylated and corresponds to the maternal allele. The lower band (4.2 $\mathrm{kb}$ ) is unmethylated and corresponds to the paternal (ICR2) allele. (C) Graphical overview of log R Ratio results obtained from the SNP array in L65P (III.7), his mother (II.3) and maternal grandmother (I.1), showing a maternally-inherited duplication in L65P and his mother. The location of the duplication is highlighted by the grey box. (D) Genomic real-time PCR quantification assay at several loci along the ICR2 domain validating the duplication. (E) DNA methylation profiles of the two $\mathrm{CpG}$ islands included in the cis-duplication determined by bisulfite sequencing in a control subject, the propositus (L65P/III.7), his mother (II.3) and maternal grandmother (I.1). Each line corresponds to an individual cloned DNA fragment and each circle represents a $\mathrm{CpG}$ dinucleotide. Methylated $\mathrm{CpGs}$ are indicated by filled circles and unmethylated $\mathrm{CpGs}$ by open circles. Parental alleles were distinguished by the rs179436 nucleotide polymorphism for the $2,510,680-2,510,907 \mathrm{CpG}$ island and the rs2074247 nucleotide polymorphism for the 2,511,982-2,512,194 CpG island. The 16 and $17 \mathrm{CpG}$ islands are framed. 
Figure 4: ICR1 deletions in BWS patients with ICR1 gain of methylation

(A) Graphical overview of log R ratio results focused at ICR1 obtained from the SNP array in BWS cases H5OP and H63P; location of deletions identified by $\log R$ ratio values are underlined with a black arrow. (B) Pedigree of the familial H63P BWS case and segregation. Subjects identified in grey developed Wilms tumors. (C) Agarose gel of PCR amplifications (position 1,976,966 to $1,981,302 \mathrm{bp}$ ) showing maternallyinherited deletions in H50P and H63P families. (D) Genomic real-time PCR quantification assay at two loci within the ICR1 domain confirmed the deletions in patients H5OP and H63P. (E) Position of the breakpoints of H63P's deletion (at 1,978,248 -1,978,293 bp and 1,980,488-1,980,533 bp) have been identified after sequencing both alleles and are highlighted on the chromatograms. The deletion removes three CTCF binding sites $(2,3$ and 4). (F) Localization of ICR1 deletions identified in this study and deletions previously described ${ }^{15-17}$.

Figure 5: Runs of homozygosity identified in control subjects and patients. Vertical lines represent length of homozygous regions. The black, light blue, dark blue and red colors represent control subjects, BWS patients with ICR1 gain of methylation, BWS patients with ICR2 loss of methylation and SRS patients with a loss of methylation, respectively. The A light grey box underlines the region encompassing the paternally-imprinted ASCL2 gene. The $B$ dark grey box underlines the region encompassing the C11ORF21 and TSPAN32 genes.

Supplementary figure 1: Schematic diagram of the $11 \mathrm{p} 15$ region with a summary of the duplications identified in the cohort and duplications previously described ${ }^{12,33,34,38}$. 
Table 1: Clinical and molecular features of patients with BeckwithWiedemann syndrome

\begin{tabular}{|c|c|c|}
\hline & $\begin{array}{c}\text { BWS with ICR2 } \\
\text { loss of methylation }\end{array}$ & $\begin{array}{c}\text { BWS with ICR1 } \\
\text { gain of methylation }\end{array}$ \\
\hline $\mathrm{n}$ & 78 & 35 \\
\hline sex $F / M$ & $36 / 42$ & $17 / 18$ \\
\hline gestational age ${ }^{a}$, weeks mean \pm SD; (range) & $36.2 \pm 3.2(27-41)$ & $36.7 \pm 3.1(30-40)$ \\
\hline ART, $n$ & 9 & 1 \\
\hline monozygotic twins & 7 & 0 \\
\hline fetal cases & 6 & 3 \\
\hline familial cases & 1 & $4^{c}$ \\
\hline \multicolumn{3}{|l|}{ phenotype } \\
\hline macrosomia at birth ${ }^{\mathrm{b}}, \mathrm{n}(\%)$ & $31 / 65(48 \%)$ & $24 / 35(69 \%)$ \\
\hline birth weight (SDS) & $1.7 \pm 1.6$ & $2.8 \pm 1.9$ \\
\hline macroglossia, n (\%) & $75 / 77(97.5 \%)$ & $31 / 33(94 \%)$ \\
\hline abdominal wall defect, n (\%) & $54 / 77(70 \%)$ & $20 / 32(62 \%)$ \\
\hline diastasis recti, $\mathrm{n}(\%)$ & 4 & 12 \\
\hline umbilical hernia, $\mathrm{n}(\%)$ & 21 & 7 \\
\hline exomphalos, n (\%) & 29 & 1 \\
\hline organomegaly, $\mathrm{n}(\%)$ & $33 / 69(48 \%)$ & $24 / 32(75 \%)$ \\
\hline body asymmetry, n (\%) & $20 / 71(28 \%)$ & $12 / 33(36 \%)$ \\
\hline hypoglycaemia, n (\%) & $26 / 63(41 \%)$ & $9 / 30(30 \%)$ \\
\hline ear abnormalities, n (\%) & $54 / 74(73 \%)$ & $9 / 30(30 \%)$ \\
\hline tumour, n (\%) & $0 / 71(0 \%)$ & $8 / 32(25 \%)^{d}$ \\
\hline \multicolumn{3}{|l|}{ others } \\
\hline ICR1 MI, mean $\pm(S D)$ & $52.8 \pm 4.1$ & $76 \pm 10.3$ \\
\hline$(N=53.9 \pm 2 \%)$ & & \\
\hline ICR2 MI, mean $\pm(S D)$ & $8.5 \pm 7.7$ & $47.9 \pm 3.8$ \\
\hline$(\mathrm{N}=51.6 \pm 2.5 \%)$ & & \\
\hline parental DNA, n(\%) & $62 / 78(79.5 \%)$ & $18 / 35(51 \%)$ \\
\hline Both parents & 57 & 14 \\
\hline One parent & 5 & 4 \\
\hline
\end{tabular}

a: gestational age is in weeks of amenorrhea

b: twins not included

c: 4 subjects from 2 families (two siblings in one family and a son and his mother in the other family)

$\mathrm{d}$ : all tumors were Wilms tumors

ART: assisted reproductive technology; MI: methylation index 
Table 2: Clinical and molecular features of patients with Silver-Russell syndrome

\begin{tabular}{|c|c|}
\hline & $\begin{array}{c}\text { SRS with ICR1 } \\
\text { loss of methylation }\end{array}$ \\
\hline $\mathrm{n}$ & 72 \\
\hline sex $F / M$ & $25 / 47$ \\
\hline gestational age ${ }^{a}$, weeks & $38.2 \pm 2$ \\
\hline ART, $n$ & 6 \\
\hline monozygotic twins & 3 \\
\hline \multicolumn{2}{|l|}{ phenotype } \\
\hline IUGR, n (\%) & $66 / 68(97 \%)$ \\
\hline birth weight $(\mathrm{SDS})^{\mathrm{b}}$ & $-3.1 \pm 0.7$ \\
\hline post-natal growth retardation, n (\%) & $61 / 64(95 \%)$ \\
\hline relative macrocephaly at birth, $\mathrm{n}(\%)$ & $59 / 62(95 \%)$ \\
\hline facial dysmorphy, n (\%) & $49 / 57(86 \%)$ \\
\hline body asymmetry, n (\%) & $51 / 68(75 \%)$ \\
\hline feeding difficulties, n (\%) & $47 / 63(75 \%)$ \\
\hline severe, $\mathrm{n}$ & 16 \\
\hline moderate, $\mathrm{n}$ & 31 \\
\hline $\mathrm{BMI}(\mathrm{SDS})$ & $-2.2 \pm 1.1$ \\
\hline $\mathrm{BMI} \leq-2 \mathrm{SDS}$ & $40 / 59(69 \%)$ \\
\hline developmental delay, $\mathrm{n}(\%)$ & $9 / 57(16 \%)$ \\
\hline clinodactyly, n (\%) & $51 / 61(84 \%)$ \\
\hline \multicolumn{2}{|l|}{ others } \\
\hline ICR1 MI, mean \pm (SD) & $23 \pm 8.3$ \\
\hline$(\mathrm{N}=53.9 \pm 2 \%)$ & \\
\hline ICR2 MI, mean \pm (SD) & $47.6 \pm 4.1$ \\
\hline$(\mathrm{N}=51.6 \pm 2.5 \%)$ & \\
\hline parental DNA, n(\%) & $30(39 \%)$ \\
\hline both parents & 22 \\
\hline one parent & 8 \\
\hline
\end{tabular}

\section{a: gestational age is in weeks of amenorrhea}

b: twins not included

ART: assisted reproductive technology; IUGR: intrauterine growth retardation; MI: methylation index 
Table 3: Copy number variations detected in SRS and BWS patients with cnvPartition v2.4.4 and QuantiSNP v2.3 softwares

\begin{tabular}{|c|c|c|c|c|c|c|c|c|c|}
\hline patients & patients' group & CNV type & origin & $\begin{array}{c}\text { parental } \\
\text { chromosome }\end{array}$ & $\begin{array}{c}\text { size } \\
\mathrm{kb}\end{array}$ & $\begin{array}{c}\text { markers } \\
\mathrm{n}\end{array}$ & $\begin{array}{l}\text { detection cnvPartition/ } \\
\text { confidence score }\end{array}$ & $\begin{array}{l}\text { detection QuantiSNP / } \\
\text { Log Bayes Factor }\end{array}$ & $\begin{array}{c}\text { qPCR } \\
\text { validation }\end{array}$ \\
\hline $\mathrm{H} 4 \mathrm{P}$ & BWS ICR1 & duplicatio & $\mathrm{NA}^{*}$ & / & 22 & 15 & yes/45.74 & no & no \\
\hline $\mathrm{H} 47 \mathrm{P}$ & BWS ICR1 & $\begin{array}{c}n \\
\text { duplicatio }\end{array}$ & de novo & paternal & $400^{\star *}$ & 526 & yes/1900.99 & yes/30.33 & yes \\
\hline L65P & BWS ICR2 & $\begin{array}{c}n \\
\text { duplicatio } \\
n\end{array}$ & inherited & maternal & 50 & 78 & yes/232.11 & yes/63.94 & yes \\
\hline $\begin{array}{l}\text { L263P } \\
\text { S63P } \\
\text { S72P }\end{array}$ & $\begin{array}{l}\text { BWS ICR2 } \\
\text { SRS ICR1 } \\
\text { SRS ICR1 }\end{array}$ & $\begin{array}{c}\text { deletion } \\
\text { deletion } \\
\text { duplicatio }\end{array}$ & $\begin{array}{l}\text { de novo } \\
\text { de novo } \\
\text { inherited }\end{array}$ & $\begin{array}{l}\text { maternal } \\
\text { paternal } \\
\text { maternal }\end{array}$ & $\begin{array}{c}4.4 \\
4 \\
80^{\star *}\end{array}$ & $\begin{array}{c}3 \\
3 \\
89\end{array}$ & $\begin{array}{c}\text { yes } / 73.93 \\
\text { yes/230.73 } \\
\text { yes/398.29 }\end{array}$ & $\begin{array}{c}\text { no } \\
\text { no } \\
\text { yes/44.24 }\end{array}$ & $\begin{array}{l}\text { no } \\
\text { no } \\
\text { yes }\end{array}$ \\
\hline
\end{tabular}

\footnotetext{
${ }^{*}$ NA: parental DNA not available

** These CNVs include the most telomeric probe of the OPA.

BWS ICR1: BWS patients with ICR1 gain of methylation. BWS ICR2: BWS patients with ICR2 loss of methylation. SRS ICR1: SRS patients with ICR1 loss of methylation.
} 
Table 4: Characterization of ICR1 deletions in BWS patients with ICR1 gain of methylation

\begin{tabular}{lccccc}
\hline & familial history & size $(\mathrm{bp})$ & breakpoints & fused repeats & $\begin{array}{c}\text { deleted CTCF } \\
\text { binding sites }\end{array}$ \\
\hline H32P & no & 1834 & $1978828-1978846 / 1980662-1980680$ & B6/B3 & 2,3 \\
H50P & no & 1834 & $1978576-1978605 / 1980411-1980431$ & B6/B3 & 3,4 \\
H63P & yes & 2240 & $1978248-1978293 / 1980488-1980533$ & B6/B2 & $2,3,4$
\end{tabular}

* Genomic positions were assigned according to the data provided by the UCSC genome browser (hg18, NCBI 36) 
Supplementary table 1: Additional primers used in this study

\begin{tabular}{|c|c|c|c|c|}
\hline Name & Localization hg18 (bp) & Sequence forward & Sequence reverse & Use \\
\hline hg18_chr11_499934/500052 & $499934-500052$ & GAAGTATTCCCACCCCCAGT & CAGATCTGTGTGGAGCAGGA & CNV validation H47P, qPCR \\
\hline hg18 chr11_1000151/1000289 & $1000151-1000289$ & TCCCAGCTGTTCCTCTCTGT & TGCAGCACTAACCACACACA & CNV validation $\mathrm{H} 47 \mathrm{P}, \mathrm{qPCR}$ \\
\hline hg18_chr11_1499784/1499923 & 1499784-1499923 & TCTAAGGCTTGGGGTTTTCC & ACAGCTCGTCCCGTAGAAGA & CNV validation H47P and S72P, qPCR \\
\hline hg18_chr11_1960213/1960314 & $1960213-1960314$ & GAGGCAAGATTTGGAAACGA & CTGGGCAGGAGACTCTGATT & CNV validation H47P and S72P, qPCR \\
\hline hg18_chr11_1977096/1977030 & 1977096-1977030 & ACGTGGAGAGGTGAATTTGC & TCСTGCTCCAGGCATTGT & CNV validation H47P and S72P, qPCR \\
\hline hg18_chr11_2123897/2124137 & 2123897-2124137 & AAACCCACATTCCACAGAGG & TCTGAGGACCCTTGGAGAAA & CNV validation $\mathrm{H} 47 \mathrm{P}, \mathrm{qPCR}$ \\
\hline hg18_chr11_2370152/2370254 & 2370152-2370254 & GGCAGAAGCAGAGGTCACA & ACACCATGCAGGTCAGACAC & CNV validation H47P, qPCR \\
\hline hg18_chr11_2375108/2375201 & $2375108-2375201$ & ССTTCATGСАССТGTССТTT & GCATGCCTGATGTTCCTTCT & CNV validation H47P, qPCR \\
\hline hg18_chr11_2155877/2156345 & $2155877-2156345$ & AGGGAAGGGGATCCAGTG & CAGACACAGACCAGCGAAAA & $\mathrm{CNV}$ validation $\mathrm{H} 47 \mathrm{P}$, Parental origin \\
\hline hg18_chr11_2371018/2371497 & 2371018-2371497 & CTGCTGAGGGATAGGGGAGT & AGTGGCATCAGAAGGCACAG & $\mathrm{CNV}$ validation $\mathrm{H} 47 \mathrm{P}$, Parental origin \\
\hline hg18_chr11_2191887/2192349 & 2191887-2192349 & GTTCСTССTGССTСССТАAC & AGAGCGGGGAAGAAACAGAT & $\mathrm{CNV}$ validation $\mathrm{H} 47 \mathrm{P}$, Parental origin \\
\hline hg18_chr11_2035226/2035462 & 2035226-2035462 & CCTCGATAGCCATTTTGCAT & GCATGGCAAAAGGAGAAAAG & $\mathrm{CNV}$ validation $\mathrm{S} 72 \mathrm{P}, \mathrm{qPCR}$ \\
\hline hg18_chr11_2107371/2107558 & 2107371-2107558 & GCTTCTGGGTCCTGGTGAC & CTCGAAGCGTTTTGGATCTC & CNV validation S72P, qPCR \\
\hline hg18_chr11_1980297/1980616 & $1980297-1980616$ & AGGTGTTTTAGTTTTTTGGATGATA & ССАТАААТАТТСТАТСССТСАСТА & $\mathrm{CNV}$ validation $\mathrm{S} 72 \mathrm{P}$, Bisulfite treatment \\
\hline hg18_chr11_2486398/2486518 & $2486398-2486518$ & AGGACCCAGACTCCCAGAC & AGGTGGTCACTGCCATCTTC & CNV validation L65P, qPCR \\
\hline hg18_chr11_2540424/2540567 & 2540424-2540567 & CTGTGTCCACCCCTCTTCAG & ACTTAGGCCTGGGGACCTT & CNV validation L65P, qPCR \\
\hline hg18_chr11_2526198/2526347 & $2526198-2526347$ & TCGGTCAGGTTAGTTGCTGT & CCCCCAGAGCTTAGGACACT & CNV validation $\mathrm{L} 65 \mathrm{P}, \mathrm{qPCR}$ \\
\hline hg18_chr11_2472491/2472581 & $2472491-2472581$ & GAAGCCCACTTGATCACCAT & GAGCACCGATGCAAAAATCT & CNV validation $\mathrm{L} 65 \mathrm{P}, \mathrm{qPCR}$ \\
\hline hg18_chr11_2676672/2677949 & 2676672-2677949 & TGGGACCCCAACTACTCAGA & AGGACACGGCACATCACTTT & CNV validation $L 65 P$, sequencing \\
\hline hg18_chr11_2677793/2679793 & 2677793-2679793 & ACCGTTCTGCCTGGAGACTG & GCCACССТСААСТСААСАТT & CNV validation L65P, sequencing \\
\hline hg18_chr11_2510633/2510968 & 2510633-2510968 & GGTTTTTGATTTTAGTAGAGGGAGG & AАACAAAAАСТСССТААААACACAТ & CNV validation $\mathrm{L} 65 \mathrm{P}$, Bisulfite treatment \\
\hline hg18_chr11_2511951/2512483 & $2511951-2512483$ & AGTGAGATTTTGTAGGGAGTTTTTG & AACCCACAAAAAAACACAACTCT & CNV validation $\mathrm{L} 65 \mathrm{P}$, Bisulfite treatment \\
\hline hg18_chr11_2674923/2675237 & 2674923-2675237 & GGAGTAGGCCAAGGATGTCA & GAGTTTTCCAGAGGCAGCAC & deletion ICR2 L65P, qPCR \\
\hline hg18_chr11_2649043/2649262 & $2649043-2649262$ & GACCTCAAAATCCGATGTCC & GGTTGCTCTTCTGCCTGCTA & deletion ICR2 L65P, qPCR \\
\hline hg18_chr11_1978454/1978696 & $1978454-1978696$ & ATGTGGCTCCCATGAATGTC & GGCTCTTGCATAGCACATGA & deletions ICR1 H50P and H63P, qPCR \\
\hline hg18_chr11_1979289/ 1979612 & 1979289-1979612 & CTGATTCCAGCAGCACAGAG & TCAGTGCAGGTTTGAGATGC & deletions ICR1 H50P and H63P, qPCR \\
\hline hg18_chr5_134898593/134898695 & 134898593-134898695 & GCTCTCTGACCCCAGTAGCC & TGTGTGGAGCAAGTCTTTGG & housekeeping gene, qPCR \\
\hline
\end{tabular}


Supplementary table 2: Runs of homozygosity detected in control subjects and patients

\begin{tabular}{|c|c|c|c|c|c|}
\hline Sample id. & Start Position (bp) & End Position (bp) & Length (bp) & Probes $(n)$ & Score Max. Log BF \\
\hline \multicolumn{6}{|c|}{ Control samples } \\
\hline CS_107 & 2264880 & 2381611 & 116732 & 210 & 37.1696 \\
\hline CS_154 & 2155554 & 2261555 & 106002 & 195 & 32.2554 \\
\hline CS_187 & 2559602 & 2690701 & 131100 & 195 & 34.3885 \\
\hline CS_189 & 2283188 & 2381611 & 98424 & 168 & 30.3942 \\
\hline CS_19 & 2128498 & 2346891 & 218394 & 408 & 101.166 \\
\hline CS_205 & 2128498 & 2261555 & 133058 & 257 & 45.1774 \\
\hline CS_245 & 2159621 & 2261078 & 101458 & 185 & 35.3047 \\
\hline CS_254 & 2155554 & 2262744 & 107191 & 199 & 33.8643 \\
\hline CS_300 & 2155554 & 2347625 & 192072 & 349 & 62.0078 \\
\hline CS_300 & 2780921 & 2869522 & 88602 & 176 & 42.9269 \\
\hline CS_315 & 2233543 & 2381611 & 148069 & 278 & 37.1292 \\
\hline CS_365 & 2233543 & 2529468 & 295926 & 507 & 62.7432 \\
\hline CS_370 & 2707910 & 2816117 & 108208 & 207 & 38.2093 \\
\hline CS_375 & 2264880 & 2381611 & 116732 & 210 & 40.529 \\
\hline CS_415 & 2412354 & 2537338 & 124985 & 188 & 37.1774 \\
\hline CŚs_7 & 2156905 & 2267446 & 110542 & 205 & 30.2087 \\
\hline CS_D & 2165989 & 2381611 & 215623 & 394 & 59.2346 \\
\hline \multicolumn{6}{|c|}{ ICR1 GOM BWS } \\
\hline AA30P & 2283727 & 2479634 & 195908 & 302 & 32.303 \\
\hline $\mathrm{H} 12 \mathrm{P}$ & 2286571 & 2381611 & 95041 & 158 & 30.3052 \\
\hline $\mathrm{H} 20 \mathrm{P}$ & 2285283 & 2381284 & 96002 & 161 & 34.5552 \\
\hline $\mathrm{H} 23 \mathrm{P}$ & 2283727 & 2425532 & 141806 & 239 & 33.3802 \\
\hline $\mathrm{H} 29 \mathrm{P}$ & 2176538 & 2387096 & 210559 & 381 & 72.3474 \\
\hline $\mathrm{H} 2 \mathrm{P}$ & 2151386 & 2261555 & 110170 & 203 & 42.128 \\
\hline $\mathrm{H} 2 \mathrm{P}$ & 2291307 & 2387096 & 95790 & 159 & 39.9038 \\
\hline $\mathrm{H} 43 \mathrm{P}$ & 1970084 & 2177516 & 207433 & 358 & 78.7391 \\
\hline $\mathrm{H} 43 \mathrm{P}$ & 2273296 & 2389540 & 116245 & 209 & 49.8905 \\
\hline $\mathrm{H} 43 \mathrm{P}$ & 2409470 & 2597296 & 187827 & 290 & 61.554 \\
\hline $\mathrm{H} 44 \mathrm{P}$ & 2156905 & 2381611 & 224707 & 407 & 90.1299 \\
\hline H54P & 2181257 & 2267728 & 86472 & 156 & 40.1736 \\
\hline H55P & 2206725 & 2381611 & 174887 & 312 & 43.1212 \\
\hline H61P & 2283727 & 2385251 & 101525 & 172 & 31.1806 \\
\hline H61P & 2644661 & 2782775 & 138115 & 264 & 53.5701 \\
\hline H69P & 2511521 & 2708236 & 196716 & 304 & 40.6492 \\
\hline H6P & 2047032 & 2381611 & 334580 & 592 & 152.827 \\
\hline $\mathrm{H} 70 \mathrm{P}$ & 2505433 & 2690701 & 185269 & 289 & 39.761 \\
\hline $\mathrm{H} 8 \mathrm{P}$ & 2144814 & 2261555 & 116742 & 217 & 49.5353 \\
\hline \multicolumn{6}{|c|}{ ICR2 LOM BWS } \\
\hline $41 \mathrm{P}$ & 2138346 & 2381611 & 243266 & 449 & 91.8929 \\
\hline $41 \mathrm{P}$ & 2423780 & 2597296 & 173517 & 269 & 31.3046 \\
\hline L101P & 2156905 & 2381611 & 224707 & 406 & 88.2207 \\
\hline L110P & 2073262 & 2261555 & 188294 & 344 & 78.5962 \\
\hline L113P & 2191119 & 2387441 & 196323 & 342 & 71.585 \\
\hline L116P & 2206725 & 2381284 & 174560 & 312 & 45.4417 \\
\hline L119P & 2497741 & 2720353 & 222613 & 354 & 65.004 \\
\hline L134P & 2582824 & 2751568 & 168745 & 270 & 34.6159 \\
\hline L138P & 2716781 & 2869522 & 152742 & 295 & 52.1911 \\
\hline L151P & 2173007 & 2262744 & 89738 & 167 & 31.3149 \\
\hline L164P & 2165989 & 2381284 & 215296 & 393 & 75.3495 \\
\hline L167P & 2399757 & 2584063 & 184307 & 290 & 54.5854 \\
\hline L170P & 2150393 & 2272679 & 122287 & 226 & 50.2314 \\
\hline L173P & 2285283 & 2388145 & 102863 & 175 & 35.2167 \\
\hline L177P & 2283188 & 2387096 & 103909 & 179 & 35.2186 \\
\hline L177P & 2559602 & 2720353 & 160752 & 248 & 40.4669 \\
\hline L186P & 2185285 & 2387096 & 201812 & 363 & 60.9426 \\
\hline
\end{tabular}




\begin{tabular}{|c|c|c|c|c|c|}
\hline L190P & 2264880 & 2387096 & 122217 & 221 & 44.6633 \\
\hline L196P & 2264880 & 2387096 & 122217 & 221 & 45.4819 \\
\hline L1P & 2156905 & 2347625 & 190721 & 346 & 47.3695 \\
\hline L203P & 2264880 & 2388145 & 123266 & 223 & 41.479 \\
\hline L20P & 2283188 & 2387096 & 103909 & 179 & 33.5019 \\
\hline L214P & 2250529 & 2529468 & 278940 & 472 & 101.227 \\
\hline L246P & 2283727 & 2381611 & 97885 & 166 & 30.5518 \\
\hline L262P & 2270670 & 2381611 & 110942 & 200 & 35.9644 \\
\hline L278P & 2250529 & 2381611 & 131083 & 244 & 49.4586 \\
\hline L39P & 2126011 & 2261555 & 135545 & 266 & 38.9765 \\
\hline L39P & 2393143 & 2505833 & 112691 & 169 & 33.0644 \\
\hline L42P & 2168253 & 2381611 & 213359 & 390 & 72.101 \\
\hline L49P & 2176538 & 2267728 & 91191 & 168 & 30.8099 \\
\hline L4P & 2000375 & 2191705 & 191331 & 332 & 44.9354 \\
\hline L4P & 2233543 & 2381611 & 148069 & 278 & 36.2062 \\
\hline L4P & 2652083 & 2764038 & 111956 & 206 & 39.2673 \\
\hline L58P & 2176538 & 2288613 & 112076 & 220 & 46.4965 \\
\hline L95P & 2039703 & 2262744 & 223042 & 386 & 111.035 \\
\hline \multicolumn{6}{|c|}{ ICR1 LOM SRS } \\
\hline $\mathrm{S} 103 \mathrm{P}$ & 2049559 & 2192166 & 142608 & 263 & 63.3619 \\
\hline S41P & 2060139 & 2177516 & 117378 & 217 & 55.3193 \\
\hline S29P & 2104733 & 2192830 & 88098 & 203 & 32.0159 \\
\hline S5P & 2130774 & 2261555 & 130782 & 252 & 48.5926 \\
\hline S122P & 2133080 & 2241585 & 108506 & 207 & 36.0915 \\
\hline S129P & 2137348 & 2246000 & 108653 & 205 & 30.2934 \\
\hline $\mathrm{S} 72 \mathrm{P}$ & 2149268 & 2261555 & 112288 & 208 & 42.3326 \\
\hline S116P & 2155554 & 2261555 & 106002 & 194 & 41.4788 \\
\hline S107P & 2156905 & 2267446 & 110542 & 205 & 46.4942 \\
\hline $\mathrm{S} 21 \mathrm{P}$ & 2156905 & 2425532 & 268628 & 480 & 118.579 \\
\hline $\mathrm{S} 75 \mathrm{P}$ & 2156905 & 2261555 & 104651 & 192 & 45.9219 \\
\hline S121P & 2159621 & 2262915 & 103295 & 192 & 44.5157 \\
\hline S115P & 2165989 & 2292816 & 126828 & 250 & 65.862 \\
\hline S104P & 2191119 & 2387096 & 195978 & 341 & 74.2499 \\
\hline S120P & 2191119 & 2308917 & 117799 & 218 & 50.8112 \\
\hline S123P & 2233543 & 2385251 & 151709 & 284 & 68.3263 \\
\hline S38P & 2233543 & 2440576 & 207034 & 372 & 67.4105 \\
\hline S95P & 2233543 & 2387096 & 153554 & 289 & 49.5405 \\
\hline S41P & 2242435 & 2445918 & 203484 & 358 & 79.6654 \\
\hline $\mathrm{S} 18 \mathrm{P}$ & 2253669 & 2381284 & 127616 & 234 & 42.2847 \\
\hline S127P & 2264880 & 2405095 & 140216 & 253 & 52.8612 \\
\hline S84P & 2264880 & 2425532 & 160653 & 281 & 68.3503 \\
\hline S32P & 2270670 & 2426669 & 156000 & 276 & 36.1267 \\
\hline S20P & 2276509 & 2385251 & 108743 & 194 & 32.2157 \\
\hline S88P & 2281815 & 2385251 & 103437 & 178 & 31.6654 \\
\hline S117P & 2283727 & 2384402 & 100676 & 171 & 38.3117 \\
\hline S60P & 2283727 & 2387096 & 103370 & 176 & 38.4677 \\
\hline $\mathrm{S} 20 \mathrm{P}$ & 2409470 & 2594837 & 185368 & 286 & 33.6277 \\
\hline S120P & 2423780 & 2543930 & 120151 & 187 & 39.6514 \\
\hline
\end{tabular}


B
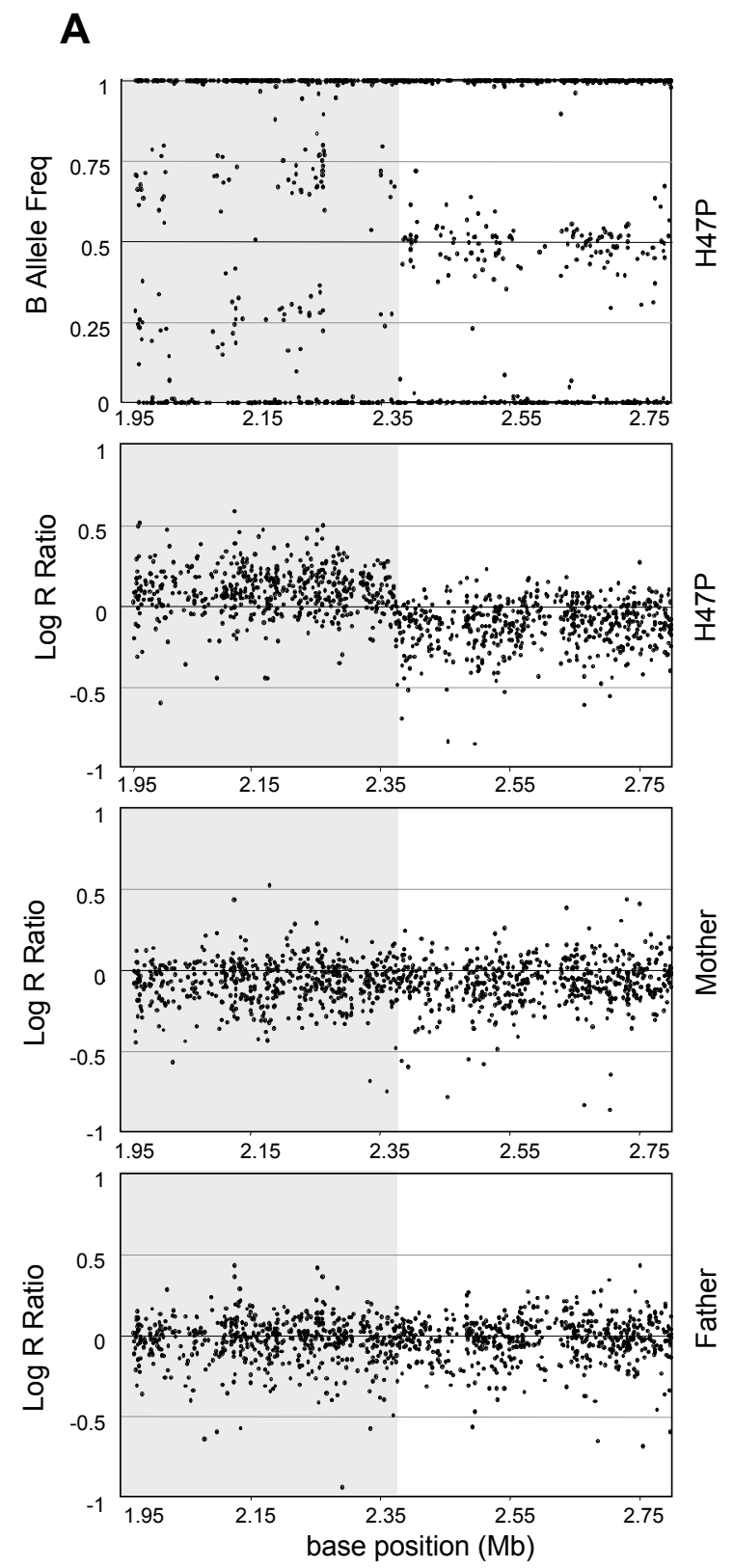

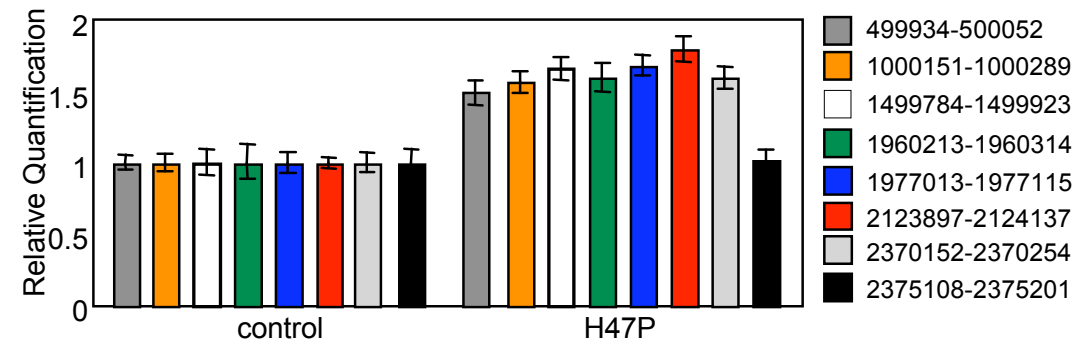

\section{C}

rs7948665 rs12803147 rs800349 $\begin{array}{lll}(2156034) & \text { (2192166) (2371278) }\end{array}$

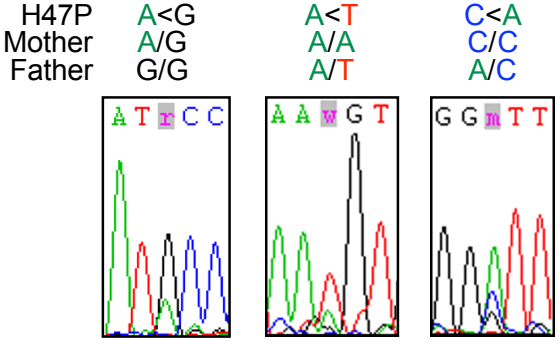

D

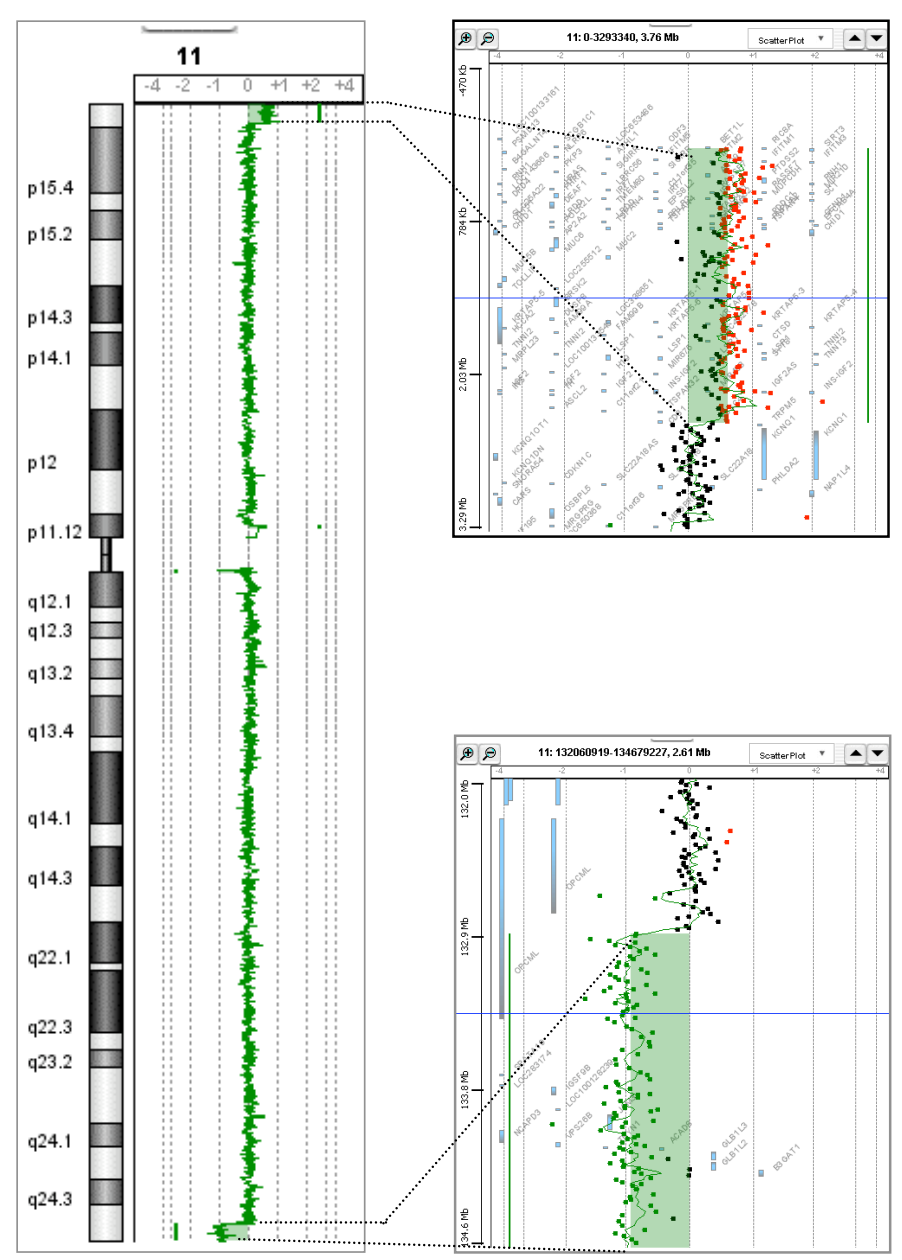

E
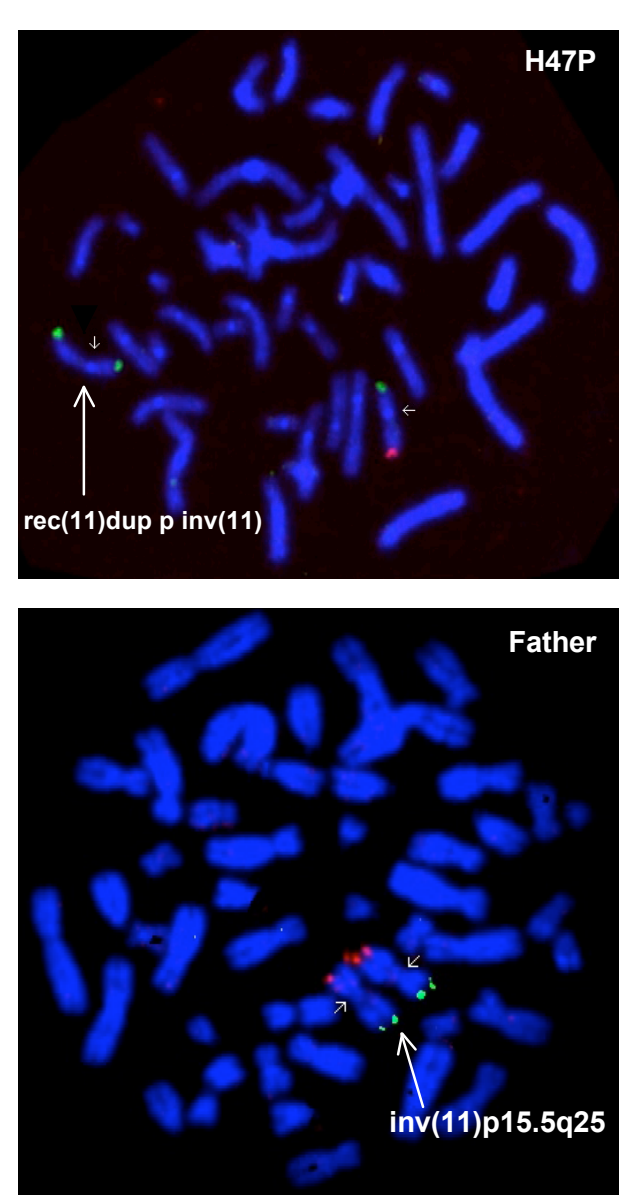

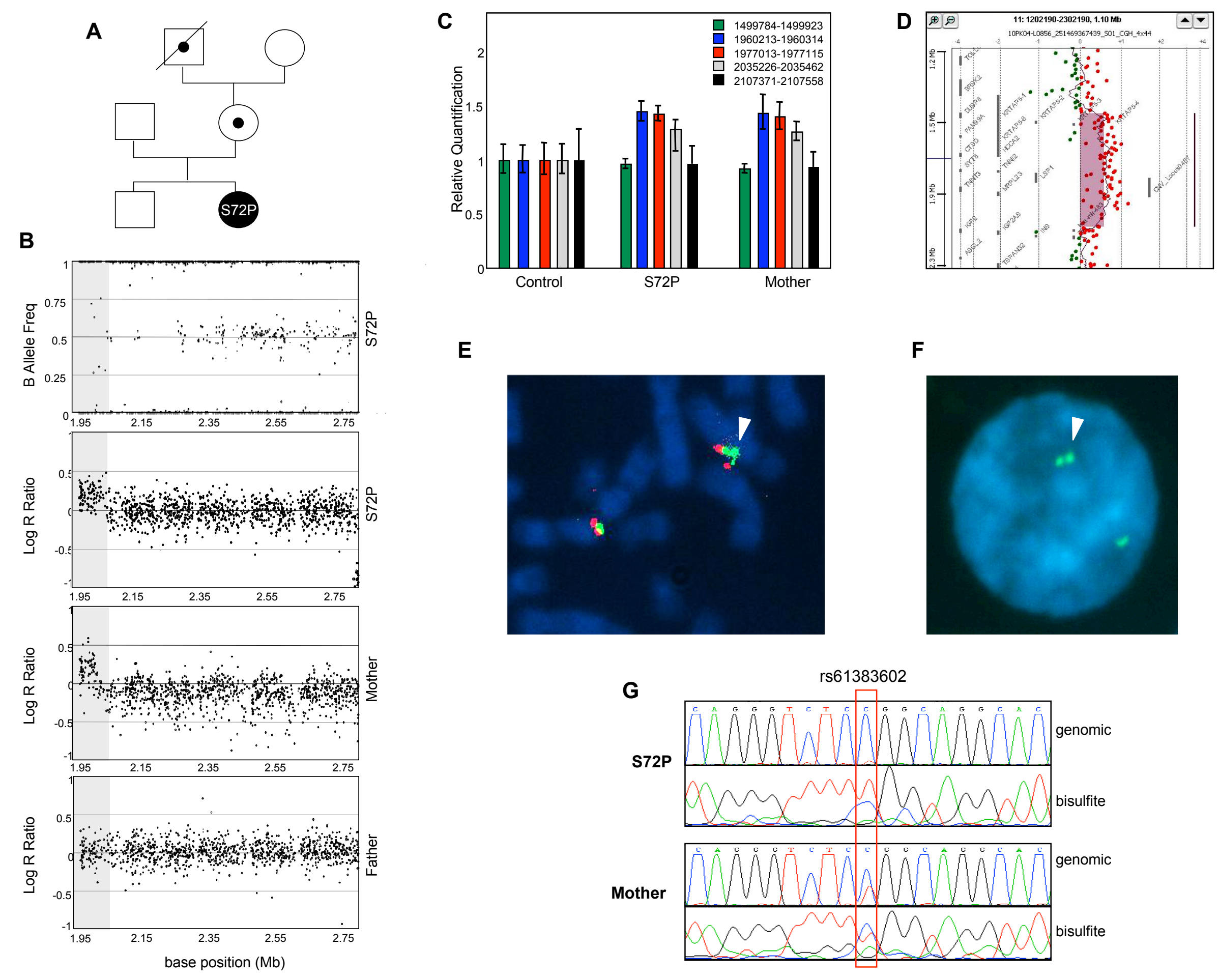

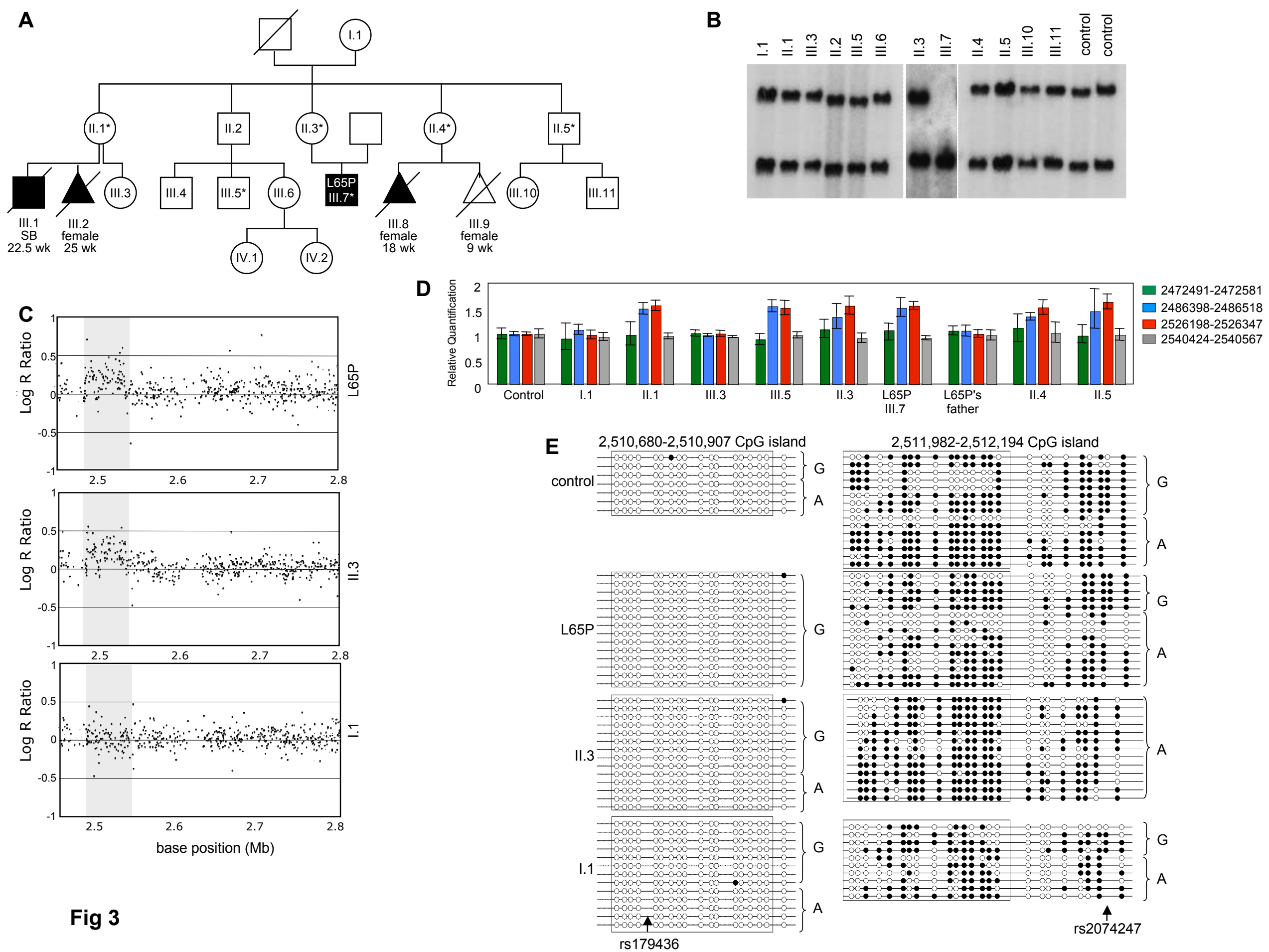

Fig 3 
A

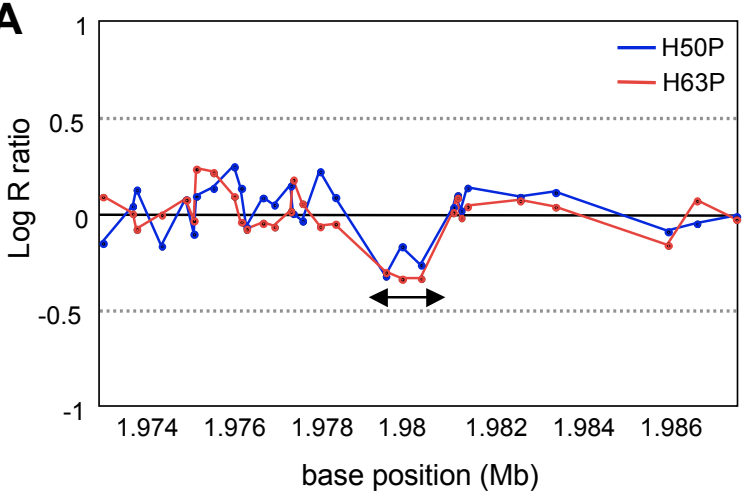

B

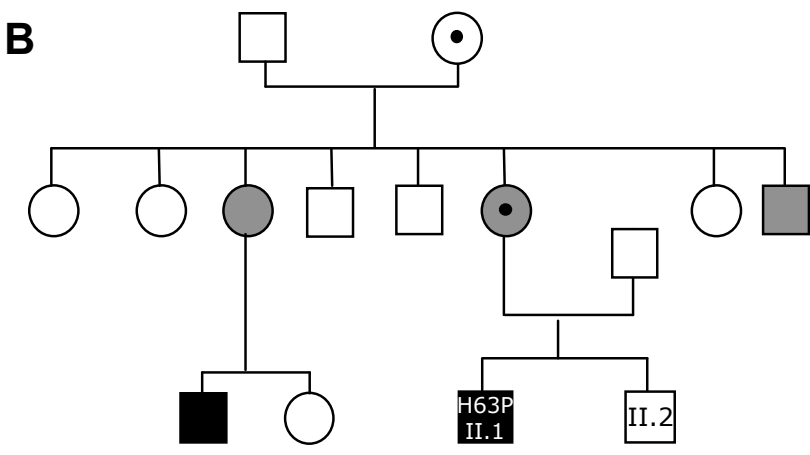

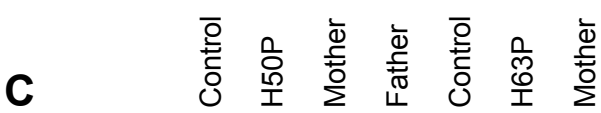

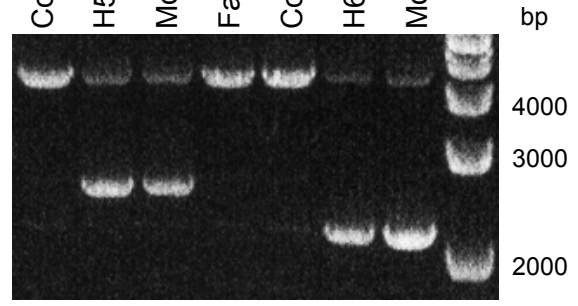

D

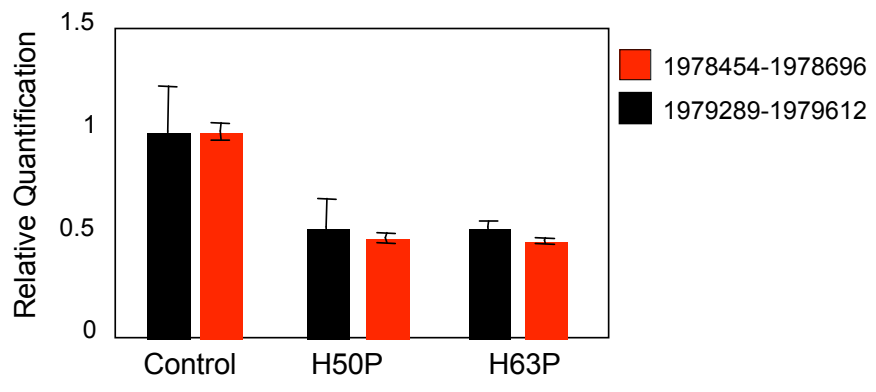

E

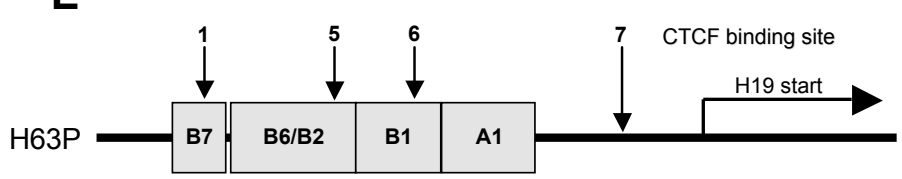

normal allele

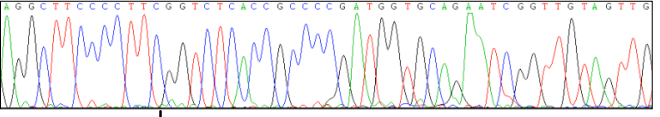

\begin{tabular}{ll|l|l|l|} 
B6 ... 1980488 & 1980487
\end{tabular}

GCTTCCCCTTC GGTCTCACCGCCCCGATGGTGC

B2 ... 1978248 $\mid$\begin{tabular}{l|l} 
AGTCTCACCGCCCGGATGGCAC \\
1978247
\end{tabular}

deleted alle

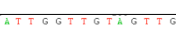

F
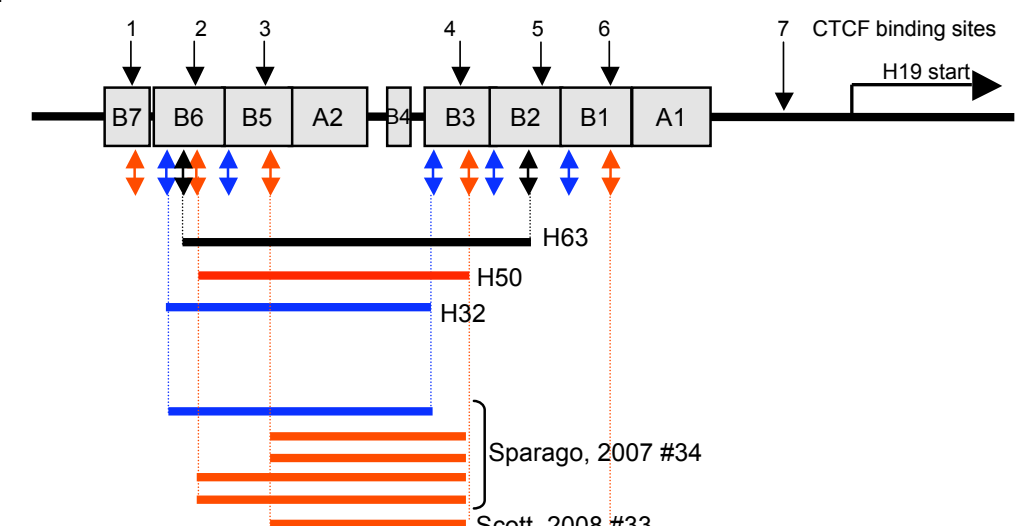


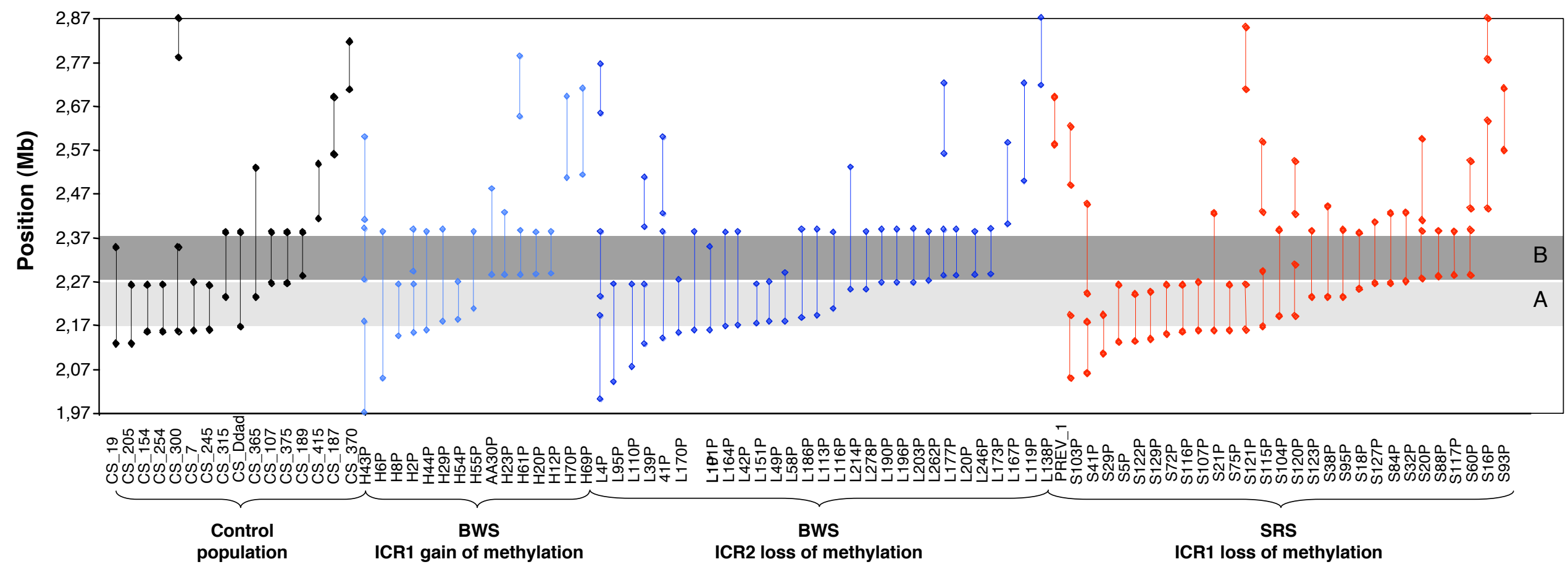




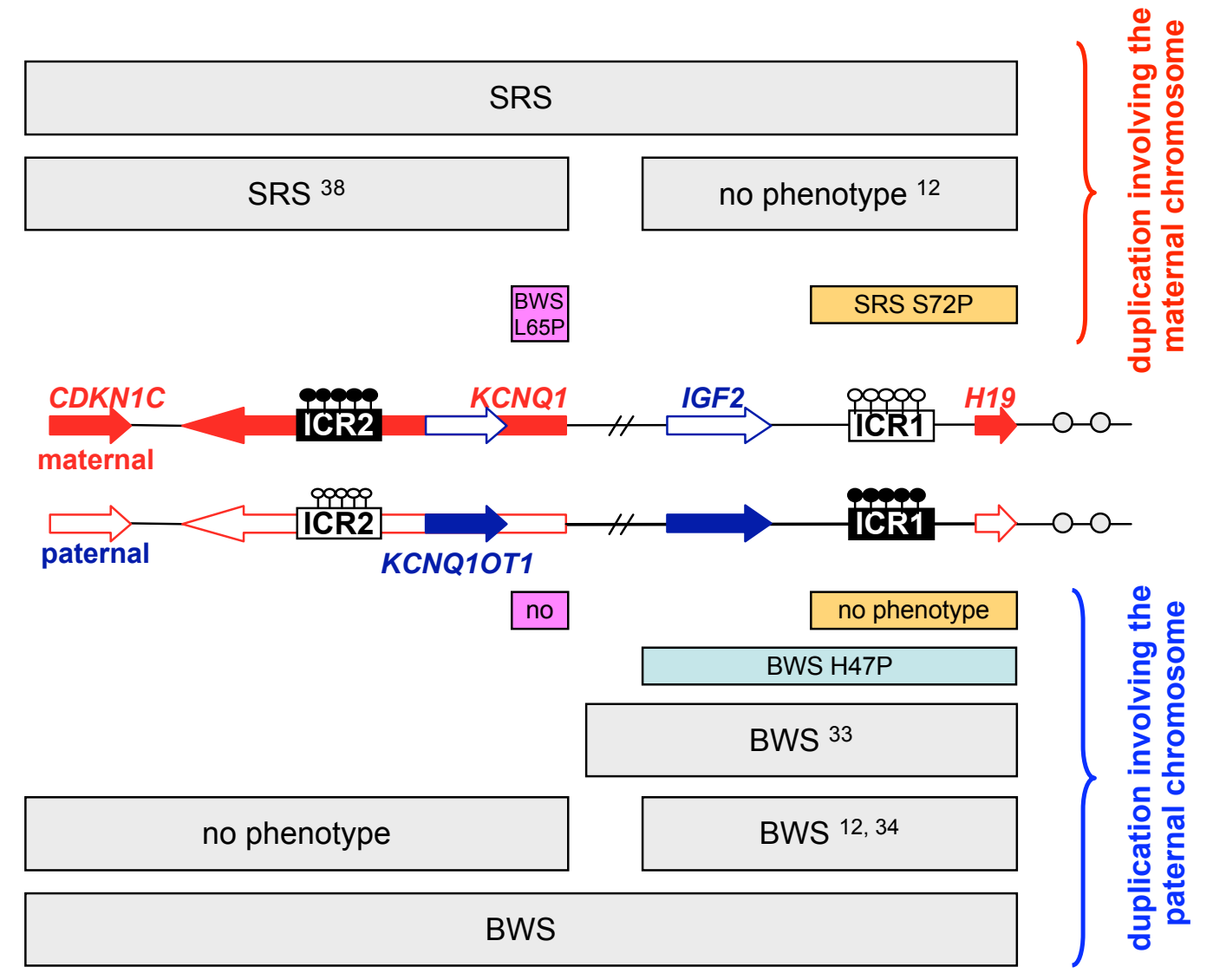

Suppl fig 1 